\title{
Springtime coupled modes of regional wind in the Iberian Peninsula and large-scale variability patterns
}

\author{
M. L. Martín, ${ }^{a *}$ F. Valero, ${ }^{b}$ A. Morata, ${ }^{c}$ M. Y. Luna, ${ }^{c}$ A. Pascual ${ }^{c}$ and D. Santos-Muñoz \\ a Departamento Matemática Aplicada a la Ingeniería, Escuela Universitaria de Informática de Segovia, Universidad de Valladolid, Pza. Sta. \\ Eulalia, 9-11 40005 Segovia, Spain \\ b Departamento Astrofísica y CC, de la Atmósfera, Facultad de CC Físicas, Universidad Complutense de Madrid, Ciudad Universitaria, s/n. \\ 28040 Madrid, Spain \\ c Agencia Estatal de Meteorología, C/Leonardo Prieto Castro, 8. 28040 Madrid, Spain
}

\begin{abstract}
This paper investigates the relationships between the Global Circulation Model (GCM)-simulated $1000 \mathrm{hPa}$ geopotential heights (taken from the ERA40 reanalysis) over the North Atlantic and the regional wind over the Iberian Peninsula for springtime (March to May). The main goal is to recognize the atmospheric circulation patterns linked to wind anomaly configurations. The method used for the downscaling is singular value decomposition (SVD). After applying a Monte Carlo approach to assess the statistical significance of the obtained modes, the SVD analysis highlighted that the covariability is dominated by three main large-scale features of the atmospheric circulation over the North Atlantic: (1) a first mode that relates local wind to the Scandinavian pattern (SCAN), by which a blocking pattern is linked to below-normal winds, (2) a second covariability mode associated with the North Atlantic Oscillation (NAO) pattern that correlates with wind over Iberia. An enhanced spring NAO pattern is related to positive (negative) wind correlations over the northern (southern) Iberia and (3) a third SVD mode that relates wind to the East Atlantic (EA) pattern promoting a dissimilar behaviour in the Iberian wind with positive (negative) wind correlations in the western (eastern) part of Iberia. To conclude, composite maps were built up to give an average circulation associated with coherent wind variability over Iberia. Copyright (C) 2010 Royal Meteorological Society
\end{abstract}

KEY WORDS Iberian Peninsula; wind speed; teleconnection patterns; singular value decomposition

Received 15 July 2009; Revised 21 January 2010; Accepted 15 February 2010

\section{Introduction}

From last decades, the world is seeing a progressive increase of interest on using sustainable and clean renewable energies. In this framework, wind energy is seen today as a proven useful technology. Nowadays, many efforts are leading to use high potential wind energy resources. The knowledge of atmospheric circulation patterns, particularly the one dealing with atmospheric patterns conducive to risky meteorological situations related to extreme wind events, is specially important for wind energy applications (Palutikof et al., 1987; Thuillier, 1987; Zuranski and Jaspinka, 1996). In that sense, the scope of several projects (ANEMOS, ANEMOS.plus, ANEMOS.eXtreme) have been forecasting, modelling and wind data assimilating for a safe large-scale wind power integration in order to finally be utilized by the end-users. Within the European Project SafeWind, several methods have been proposed in order to analyse the overall wind

\footnotetext{
* Correspondence to: M. L. Martín, Departamento Matemática Aplicada a la Ingeniería, Escuela Universitaria de Informática de Segovia, Universidad de Valladoli. Pza. Sta. Eulalia, 9-11 40005 Segovia, Spain. E-mail:mlmartin@eis.uva.es
}

energy situation over an area of interest by a spatialtemporal analysis of meteorological and wind power measurements. Then the final analysis could subsequently be used for nowcasting wind power over the whole area, and for data assimilation purposes (in order to update and improve wind power predictions) for better understanding the spatial-temporal characteristics of prediction errors, or for issuing 'global' warnings related to expected accuracy of weather and wind power forecasts over the area considered.

Atmospheric circulation variability constitutes one of the most important factors in determining temporalspatial distribution changes of variables such as wind, precipitation, temperature and other climatological elements. The Western European climate steps necessarily on the available knowledge of natural variability in regional scales and its relationship to large-scale circulation (Deser and Blackmon, 1993; Esteban-Parra et al., 1998; Rodriguez-Puebla et al., 1998). Western European climate is to some extent characterized by the North Atlantic Oscillation (NAO) which is, particularly during winter, the first teleconnection pattern of low frequency (Barnston and Livezey, 1987; Glowienka-Hence, 1990; Rogers, 1990). Although the influence of the NAO on the Western Mediterranean climate has been discussed 
by a number of authors (Corte-Real et al. 1995; Hurrell and van Loon, 1997; Maheras et al., 2001), there are other modes of variability that can also affect the Western Mediterranean climate (Luna et al., 2001; Martin et al., 2004; Valero et al., 2004). The relative location of different pressure centres over the North Atlantic area influences different air masses with distinct physical characteristics over Iberia to produce a wide range of differentiated regional climates (Font, 2000). Moreover, the complex topography of the Iberian Peninsula plays a leading role in the characterization of the regional atmospheric variability. As a matter of fact, at local scales, topography is a decisive factor in the development of cloud systems or in the enhancement of wind speed over different areas, while at larger scales, the synoptic and mesoscale flows are generated or redirected.

The present study is focused on the linkage between observed wind fluctuations on the Iberian Peninsula and surface circulation anomalies during the spring season. The main purpose is to identify atmospheric circulation patterns occurring simultaneously with wind anomaly configurations with special emphasis on episodes of strong anomalies of wind. If the large-scale circulation configurations are associated with typical surface wind circulation patterns, mechanisms forcing regional atmospheric variability will be better understood. To do this, the singular value decomposition (SVD) is applied to large-scale atmospheric variables, such as geopotential height and wind field in order to analyse their relationships. The multivariate techniques have been successfully used by the authors (Martin et al., 2004; Sotillo et al., 2006; Valero et al., 2009) in other studies to gain a better insight into the seasonal relation between large-scale circulation anomalies and regional variable fluctuations, giving evidence of the influence of several North Atlantic teleconnection patterns of low frequency on the variability of the regional variables in the Western Mediterranean area (Morata et al., 2006; Sotillo et al., 2006; Morata et al., 2008; Valero et al., 2009). In contrast to these studies, which used monthly mean geopotential heights at upper atmospheric levels, this paper will be confined to the near-surface geopotential heights for representing the large-scale atmospheric circulation at a more realistic height level to obtain more accurate circulation patterns with the observational wind speed field over Iberia. In addition, the study of the relationship between the spring wind variability and the teleconnection patterns has been reinforced by means of wavelet transforms and composite analyses.

The study is organized as follows. A brief description of the datasets and different winds affecting the Iberian Peninsula is given in Section 2. Section 3 is devoted to describe the methodology applied to the original datasets and some obtained results. Section 4 is devoted to analyse the Iberian wind variability and its connection with the low-level atmospheric circulation taking into account the statistical significance of the coupled modes. Section 5 offers the results from the composites maps obtained from the extreme data statistically derived from the previous section. The summary and discussion of the main results are drawn in Section 6.

\section{Data and Iberian Winds}

Two data sets have been used in this study: monthly mean geopotential heights of the $1000 \mathrm{hPa}$ (G1000) and monthly mean wind data for 48 stations distributed over Iberia (Figure 1(a)), during the spring [March-April-May (M-A-M)] season from 1980 to 2001. Monthly mean G1000 data are a product of the ERA40 reanalysis (Gibson et al., 1997; Simmons and Gibson, 2000). The G1000 data are given on a $1.2^{\circ} \times 1.2^{\circ}$ latitude $\times$ longitude grid (Figure 1(b)), spanning a domain from $52^{\circ} \mathrm{W}$ to $16^{\circ} \mathrm{E}$ and $20^{\circ}$ to $60^{\circ} \mathrm{N}$ for 22 -spring (1980-2001). Wind data used in this paper consists of time series of daily speed wind from 48 sites over the Iberian Peninsula (station locations will be displayed by dots in the displays), covering the 1980-2001 period. These data come from in situ measurements of the station network of the Spanish Meteorological Service (Agencia Estatal de Meteorología, AEMET). From the daily data, monthly mean wind speed field has been obtained over the 22-year period. The list of stations used and their geographical coordinates are shown in Table I. Prior to the diagnostic analysis, all data sets were modified applying a cos (latitude) square root area-weighting to account for the uneven spatial density of the grid.

Concerning wind regime, Iberia is characterized by a maximum strength in spring, minimum in summer and high frequency of calm in winter, exhibiting important climatic contrasts. The Northern Peninsular area is mainly affected by cold dry or moist wind, depending on the air mass origin, while the south of Iberia is affected by southwestern warm dry winds coming from the North Africa area or by warm wet air masses coming from the southeast. To quote some winds as an example (Figure 1(c)), the Mediterranean Peninsular coast is affected by wet winds named Levante or by wet and warm air masses coming from Sahara, the Xaloc. The northwestern (southeastern) cold (warm) dry (moist) winds blowing down (up)-valley Ebro are known as Cierzo (Bochorno) while west-northwestern moist cold winds, named Galerna blow the Cantabric coasts (Garcia, 1985; Font, 2000). On the other hand, Tramontana are northern or northeastern winds affecting Catalonia and the Balearics. Southern Iberia is influenced by winds such as Ábrego with different characteristics to those of the northern Peninsula. Therefore, there are significant northern-southern differences, advection of west-east air mass with diverse characteristics, influence of orography and land-sea temperature contrasts. Extreme wind events have disastrous consequences that can affect natural ecosystems and several aspects of societies. Therefore, advances in understanding the relationships of wind anomalies in the Iberian Peninsula with coherent atmospheric anomaly patterns constitute an issue of relevance. 
(a)

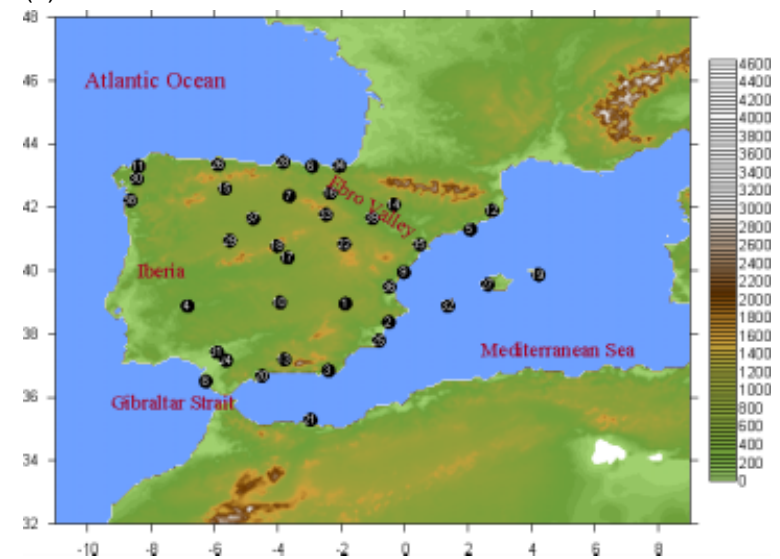

(b)

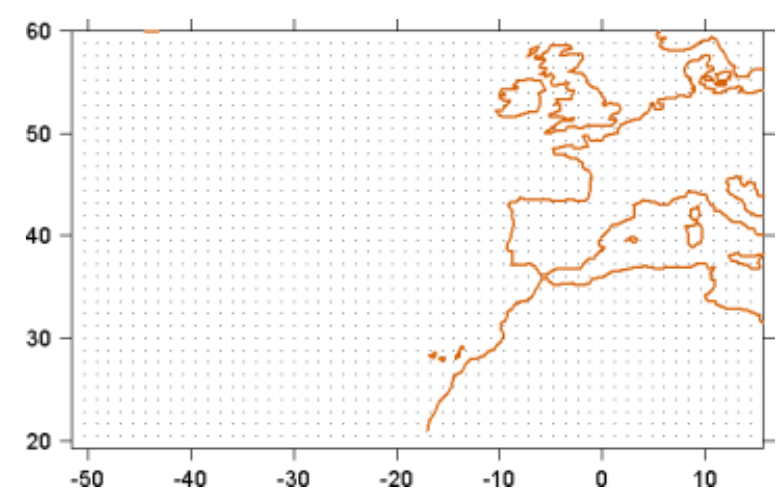

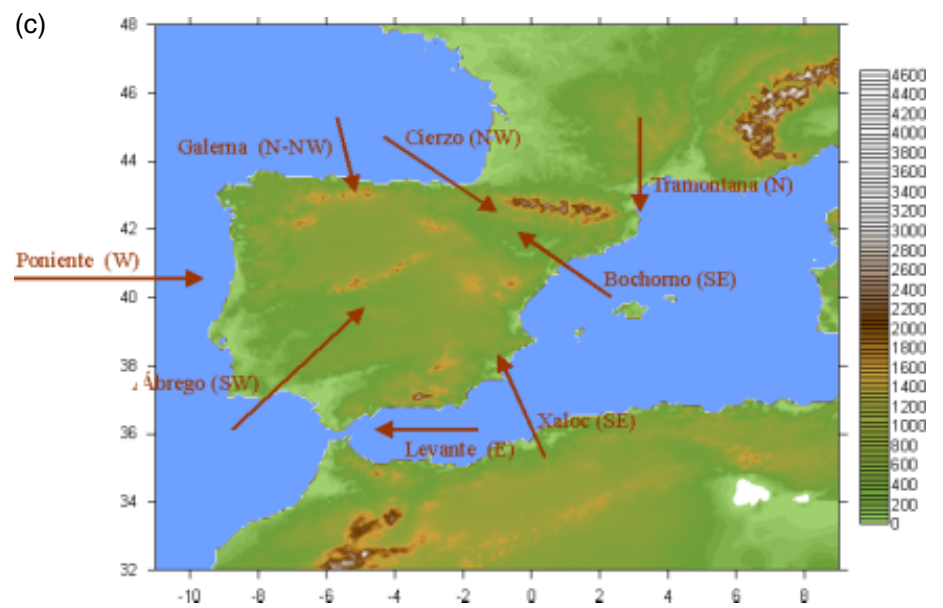

Figure 1. (a) Circles indicate the wind stations for the Iberian Peninsula with its orography detailed. The station codes are shown in Table I. The $x$-axis corresponds to longitude, positive (negative) for degree east (west). The $y$-axis to latitude, positive for degree North. (b) The large-scale study domain $\left(52^{\circ} \mathrm{W}-16^{\circ} \mathrm{E}, 20^{\circ}-60^{\circ} \mathrm{N}\right)$ is framed. (c) The Iberian Peninsula with typical winds and directions superimposed. This figure is available in colour online at wileyonlinelibrary.com/journal/joc

\section{Methods}

The relationship between the large-scale atmospheric circulation and wind in the Iberian Peninsula is analysed by means of the singular value decomposition analysis (SVDA). Here, we give only a brief description of the method. Nevertheless, if more details about SVD are required, they can be found for example in the study of Bretherton et al. (1992) and von Storch and Zwiers (1999). The analysis based on SVD can be thought of as a generalization of the diagonalization of a square symmetric matrix to the diagonalization of a rectangular one, i.e. it is a generalization of Empirical Orthogonal Functions (EOF) (Lorenz, 1956; Davis, 1976). SVDA has usually been applied to two data fields together in order to identify modes that explain the greatest covariance between such fields. An SVD of the crosscovariance matrix of the two data fields yields two sets of orthogonal singular vectors describing a squared covariance fraction (SCF) of two time series. The SCF represents the percentage of the squared covariance (SC) explained by a pair of patterns. These singular vectors are also called left and right patterns or modes. Moreover, the modes are ordered with respect to their singular values so that the first pair accounts for the largest SCF and the remaining pairs describe a maximum fraction unexplained by the previous pairs (in analogous manner to the eigenvalues in Principal Component Analysis (PCA)). In fact, the interpretation of the left and right singular vectors is a natural extension of the EOF concept (von Storch and Navarra, 1995). Each singular value measures the contribution of each corresponding pair of modes to the total SC. Thus, the SCF accounted for by the $i$ th pair of singular vectors is proportional to the square of its singular value. If the $i$ th singular left (right) vector is projected onto each data field, the $i$ th left (right) expansion coefficient for each variable can be obtained. The correlation, $r$, between the $i$ th expansion coefficients of the two variables measures how close the relationship between the pairs is (Hu, 1997). The homogeneous correlation pattern for the $i$ th left (right) field is defined as the vector of correlation coefficients between the grid point values of left (right) field and the $i$ th left (right) expansion coefficient time series. The homogeneous correlation pattern is related to the EOF of the corresponding field, showing the strength of the pattern. The heterogeneous correlation pattern for the $i$ th left (right) field is defined as the vector of correlation coefficients between the grid point values 
Table I. List of stations used indicating the code for Figure 1(a), name, longitude, latitude and altitude.

\begin{tabular}{|c|c|c|c|c|c|}
\hline 1 & ALB & Albacete & 38.95 & -1.86 & 704 \\
\hline 2 & ALI & Alicante & 38.37 & -0.49 & 82 \\
\hline 2 & ALI-Ae & Alicante (Aeropuert & 38.29 & -0.56 & 31 \\
\hline 3 & ALM & Almeria & 36.84 & -2.39 & 20 \\
\hline 4 & $\mathrm{BAD}$ & Badajoz (Talavera) & 38.88 & -6.83 & 185 \\
\hline 5 & BAR & Barcelona & 41.3 & 2.08 & 6 \\
\hline 6 & BIL & Bilbao & 43.3 & -2.91 & 39 \\
\hline 7 & BUR & Burgos (Villafria) & 42.36 & -3.63 & 890 \\
\hline 8 & CAD & Cadiz (Cortadura) & 36.5 & -6.26 & 8 \\
\hline 9 & CAS & lón (Almazora) & 39.95 & -0.02 & 35 \\
\hline 10 & $\mathrm{CIU}$ & Ciudad Real & 38.99 & -3.92 & 627 \\
\hline 11 & COR-Ae & A Coruña (Aer & 43.3 & -8.38 & 97 \\
\hline 11 & COR & $\mathrm{A} \mathrm{C}$ & 43.37 & -8.42 & 58 \\
\hline 12 & GIR & Girona & 41.9 & 2.76 & 127 \\
\hline 13 & GRA & Grar & 37.19 & -3.78 & 570 \\
\hline 14 & HUE & Huesc & 42.08 & -0.33 & 541 \\
\hline 15 & LEO & León & 59 & & 916 \\
\hline 16 & LOG & Log & 15 & -2 & 352 \\
\hline 17 & MAD & $\mathrm{N}$ & & -3 & 667 \\
\hline 17 & MAD-Ae & (Aer & 40.45 & -3 & 582 \\
\hline 17 & MAD-Cu & $\mathrm{Mac}$ & 40.38 & -3 & 687 \\
\hline 17 & MAD-Ge & $\mathrm{Ma}$ & 40.3 & -3.72 & 617 \\
\hline 18 & MAD-Na & $\mathrm{Ma}$ & 40.78 & -4.01 & 1890 \\
\hline 19 & MAH & $\mathrm{N}$ & 39 & 4.23 & 85 \\
\hline 20 & MAL & Mal & 36.67 & -4.49 & 7 \\
\hline 21 & MEL & $\mathrm{N}$ & 35.28 & -2 & 55 \\
\hline 22 & MOL & Mo & 34 & -1.89 & 1063 \\
\hline 24 & MOR & & 37 & -5.62 & 87 \\
\hline 24 & MUR-Al & cantarilla) & 37.96 & -1.23 & 85 \\
\hline 25 & MUR-SJ & Mur & 37.79 & -0.8 & 2 \\
\hline 26 & OVI & Ovi & 35 & -5 & 336 \\
\hline 26 & RAN & & 56 & -6.03 & 127 \\
\hline 27 & PAL & & & 2.63 & 3 \\
\hline 27 & PAL-Ae & Paln & 39.57 & 2.74 & 4 \\
\hline 28 & PAR & Par & 43.43 & -3.82 & 6 \\
\hline 29 & SAL & Sala & 40.95 & -5.5 & 790 \\
\hline 30 & $\mathrm{SCO}$ & Santi & 42.9 & -8.43 & 364 \\
\hline 31 & SEV & Sevil & 37.42 & -5.9 & 26 \\
\hline 32 & SJO & San & 38.88 & 1.37 & 16 \\
\hline 33 & SOR & Soria & 41.77 & -2.47 & 1082 \\
\hline 34 & SSE & San Sebastian & 43.31 & -2.04 & 252 \\
\hline 35 & TOR & Tortc & 40.82 & 0.49 & 48 \\
\hline 36 & VAL & Vale & 39.49 & -0.47 & 57 \\
\hline 37 & VALL & Valladolid & 41.65 & -4.77 & 735 \\
\hline 37 & VALL-Vi & Valladolid (Villanubla) & 41.7 & -4.85 & 846 \\
\hline 38 & VIG & Vigo & 42.22 & -8.63 & 255 \\
\hline 38 & ZAM & Zam & 41.52 & -5.73 & 656 \\
\hline 39 & ZAM-Ae & Zamora (Aeropuerto) & 41.66 & -1.01 & 247 \\
\hline
\end{tabular}

of left (right) field and the $i$ th right (left) expansion coefficient time series. For display purposes, the time series of expansion coefficients have been normalized by their standard deviation. The SVD was then performed on the detrended data to obtain seasonally independent detrended modes. The expansion coefficients are obtained by projecting the original data (i.e. non-detrended) onto the previously derived SVD spatial modes. This allows for a representation of the long-term trends in the time series of expansion coefficients while the initial detrending of data avoids inflation of the cross-covariance coefficients in the determination of the spatial SVD patterns (Heyen et al., 1996; von Storch and Zwiers, 1999).

On the other hand, in order to get information about all timescales of the time series derived through the paper, a wavelet transform analysis has been carried out. The wavelet transform technique was introduced and formulated by Morlet et al. (1982) and Grossman and Morlet (1984). Wavelet transforms have been applied successfully to different studies of meteorological and climatological time series so as to understand their temporal scales of variability (Gamage and Blumen, 1993; Gao and Li, 1993; Weng and Lau, 1994; Morata et al., 2006; Barbosa et al., 2009). These studies highlight the advantages of the technique compared with Fourier transform analysis as the former plays down the difficulty of showing structures on different time or spatial scales at different time or spatial locations. The Fourier transform does not contain any time dependence on the signal, hence not providing any local information regarding the time evolution of its spectra. One of the differences with the Fourier transform is that wavelets enable localization in frequency and in time (Morlet et al., 1982), turning to be an appropriate and powerful tool to study time series. The wavelet transformation has not only good local properties in time and frequency domain, but it also works as a microscopic analytical function by decomposing a time series into a set of scale components. Like Fourier sines and cosines, wavelets are basis functions that can be used to represent any given signal because of wavelets contain information about frequencies of the signal over all times instead of showing the frequency variations in time. Wavelet transforms are built as translations and dilations of a mother wavelet or wavelet function and of a scaling function. Wavelets are characterized by pairs of the mother orthogonal functions interpreted as impulse response to bandpass filter, and scaling functions that can be interpreted as impulse response to low-pass filter (Kaiser, 1995; Mallat, 1998). Furthermore, it allows discrimination between oscillations occurring at fast scales and others at slow scales (Morlet et al., 1982; Grossman and Morlet, 1984; Morata et al., 2006; Morata et al., 2008). Additionally, the continuous wavelet analysis has the advantage of being usually easier to interpret because all the information tends to be more visible. In this paper, the continuous wavelet transform was used as a filter to decompose and isolate characteristics (Mallat, 1998) of the time series at different frequencies.

Additionally, the relationship between observational patterns and the coupled modes obtained from the SVD is studied by directly constructing positive (negative) composites from a number of months with the highest (lowest) values of the expansion coefficients. While the derived modes are statistically built, the composite maps represent configurations of the variable which can be comparable to observations. The choice of the number of situations has been arbitrary and chosen to be $5 \%$ of the total number of cases in the dataset: approximately 4 
situations of 66 total data for the positive composite and other 4 situations for the negative one. This number of data cases is enough to be representative of the observe patterns linked with strong wind anomalies.

Finally, a Monte Carlo test was performed to assess the statistical robustness of the SVD results. The test allowed to determine the statistical significance of the leading SVD modes and to indirectly estimate the relative importance of the large-scale atmospheric circulation over the regional wind field. Instead of using the SCF or the correlation coefficient, the abovementioned SC was taken into account as it does not measure the percentage of the covariance explained by a pair of patterns, but the direct relationship between the surface and wind fields and between the coupled SVD patterns; the SCF and the correlation, $r$, are indirect measures of the relationship between the SVDA modes. Thus, a large SCF and $r$ in the leading SVD modes of the two weakly related fields can be found, even though these modes actually account for little SC (Wallace et al., 1992). Therefore, the SCF and $r$ are meaningful only when they are associated with a significant SC. If two strongly related datasets are scrambled, their relationship becomes worse to some extent, being reflected directly in the total SC as well as in the SC of each SVD mode. Therefore, the statistical significance of the total SC and the SC of the first SVD modes will be tested by a Monte Carlo approach. The procedure is similar to the one described in the work by Wallace et al. (1992) to perform an ensemble of SVDs of several scrambled datasets. Basically, the procedure consists of building a scrambled dataset by only scrambling each synoptic G1000 pattern of 22 years in order to destroy its chronology relative to the wind field. The G1000 field is randomly ordered in the time domain, invalidating its original order with the order of the wind speed field preserving the spatial coherence of the observed fields and not their properties in time. This procedure is repeated 100 times, i.e. a set of 100 of such scrambled datasets is built. On the other hand, an SVD is performed over each scrambled dataset and the wind speed field, and thereby obtaining 100 SVDs. Finally, these results are compared with those obtained from the original unscrambled data. An SC from the observed G1000 field and the wind dataset is considered statistically significant at the $95 \%$ level if it is not exceed more than five times by the corresponding ones from the 100 scrambled datasets. If lesser than five scrambled SC values are found to be greater than the observed SC then the observed SC is significant.

\section{Results of the Coupled Patterns}

In this section, the relationships between the Iberian wind field and the large-scale atmospheric circulation patterns are investigated by means of an SVD analysis, and the results are analysed from testing their statistical significance. The analysis is carried out diagonalizing the covariance matrix between wind and G1000. Finally, the true circulation characteristics related to the correlation patterns will be exposed by composite maps. Table II shows the percentage of the SCF and the temporal correlation between the pairs of expansion coefficients for the first modes of the SVD analysis, to give us an idea of the strength of the coupling. From the analysis and, as it will be specified in the Monte Carlo results at the end of the section, only the three first coupled modes, accounting for $93 \%$ of accumulated covariance, are considered. The leading coupled modes closely resemble the PCA patterns (not shown) of the corresponding fields, thus, representing recurrent physically coupled modes $(\mathrm{Hu}$, 1997). In addition, for the three first modes the correlation values are higher than for the remaining ones. Then it seems consistent to try and to analyse the main features of the coupled SVD patterns for the three first modes of covariability.

\subsection{First mode of covariability}

The first SVD mode (SVD1) explaining $73 \%$ of the SC between monthly mean G1000 and wind fields is shown in Figure 2. The G1000 pattern (Figure 2(a)) depicts a nucleus of positive correlations centred over central Europe. This configuration of blocking promotes advection of eastern air mass over the Iberian Peninsula, favouring eastern flows over the Mediterranean Iberian zone (Holton, 1992; Bluestein, 1993). The wind (Figure 2(b)) presents similar behaviour over the whole Peninsula, depicting negative wind correlations in the whole area except for the Gibraltar area. This pattern in which normal coastline air masses are blowing in the mouth of the Ebro river with associated southeastern moist winds blowing up-valley Ebro corresponds to Bochorno (Garcia, 1985). Moreover, it is noticeable the channelling effect along the Gibraltar Strait with negative/positive correlations along it. Table III shows the variances of individual fields explained by the three first significant modes. The wind pattern described by the first SVD mode accounts for about $20 \%$ of the total wind variance and matches the first homogeneous mode of this variable (not shown) which accounts for $35 \%$ of the wind variability. The agreement between the wind SVD pattern and its corresponding homogeneous mode is indicative not only of the intensity of the obtained heterogeneous pattern but also of the strength of the

Table II. Squared covariance fraction, SCF and temporal correlation coefficient, $r$, for the first five modes of SVD analysis corresponding to the pairs of coupled patterns.

\begin{tabular}{lcc}
\hline $\mathrm{K}$ & \multicolumn{2}{c}{ G1000 -Wind } \\
\cline { 2 - 3 } & $\mathrm{SCF}(\%)$ & $r$ \\
\hline 1 & 73 & 0.70 \\
2 & 14 & 0.62 \\
3 & 8 & 0.62 \\
4 & 2 & 0.57 \\
5 & 2 & 0.45 \\
\hline
\end{tabular}


(a)

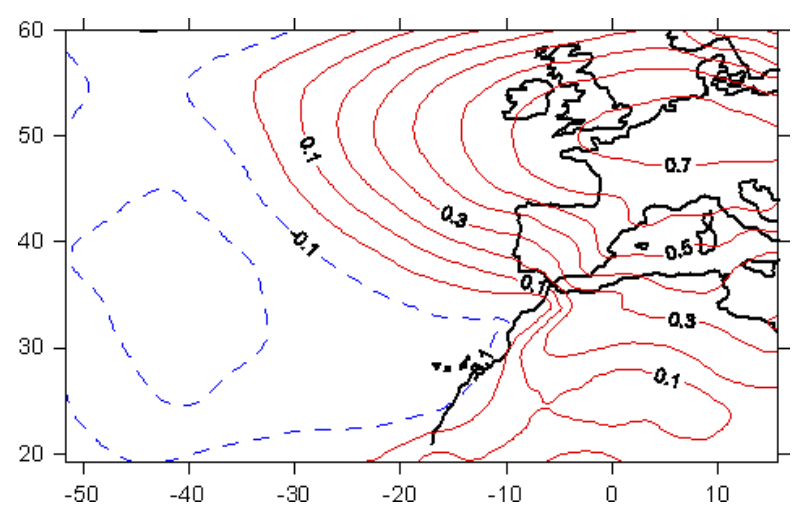

(b)

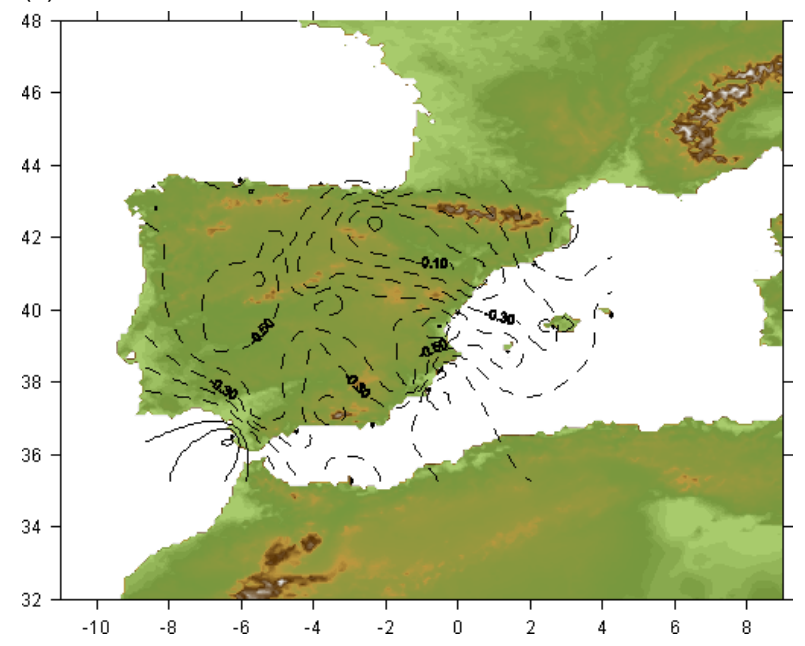

(c)

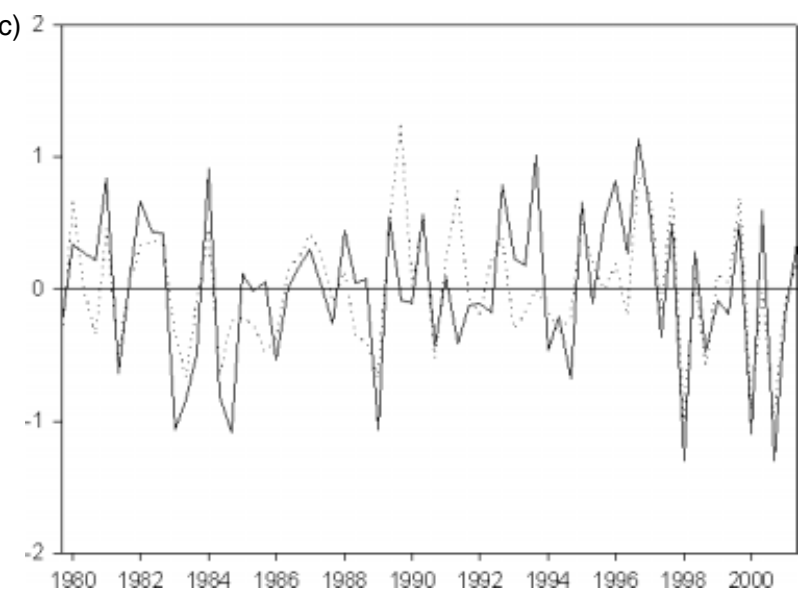

Figure 2. Heterogeneous patterns of the SVD1: (a) G1000 and (b) wind. The positive (negative) correlations are solid (dashed). (c) Expansion coefficient time series of the wind (continuous line) and G1000 (dashed line) of the SVD1 mode. Units are in standard deviations in the $y$-axis, and the $x$-axis corresponds to the time period. This figure is available in colour online at wileyonlinelibrary.com/journal/joc

link between the large-scale pattern and the wind field. The associated G1000 pattern explains $10 \%$ of variance (Table III) and it agrees reasonably well with its corresponding first homogeneous mode, accounting for $23 \%$ of the G1000 variability, which matches to the well-known teleconnection pattern named Scandinavian (SCAN) pattern (Rogers, 1990). The SCAN pattern is one of the most prominent teleconnection patterns which affects Eurasia throughout year. This pattern has been referred to as the Eurasia-1 pattern by Barnston and Livezey (1987). The SCAN pattern is characterized in its negative (positive) phase by a north-south dipole of anomaly centres with a negative (positive) node centred over Scandinavia and another positive (negative) centre over Western Europe. The absolute correlation value between the large-scale first expansion coefficient time series and the time series of the SCAN pattern is 0.6 , indicating that the SVD1 relates the wind in the Iberian Peninsula to such teleconnection mode of variability.

The SVD1 time series are shown in Figure 2(c). In general, similar time evolution can be observed in all cases. The moderately high correlation values $(r=0.70)$, significant at the 0.01 level, between the
Table III. Variance of individual fields explained by the three first modes of the SVD analysis.

\begin{tabular}{lcc}
\hline $\mathrm{K}$ & G1000 variance & Wind variance \\
\hline 1 & 11 & 20 \\
2 & 9 & 7 \\
3 & 7 & 4 \\
\hline
\end{tabular}

The variance is in percent.

pairs of time series (Table II) points to the high degree of coupling between the large-scale variables and the regional wind. In order to examine the year-to-year fluctuations of the Iberian wind field, the spatial averages of the 48 standardized mean wind speed time series are derived and shown in Figure 3(a). The spatial average mean wind speed is characterized by a mixture of wind interannual fluctuations up to 1989 and five-year fluctuations after 1989, approximately with above-normal conditions followed by a long period that contains the below-normal springs. It should be noticed that the three below-normal years lie in the later period, having 1997 the lowest value and most anomalous wind year. 
(a)

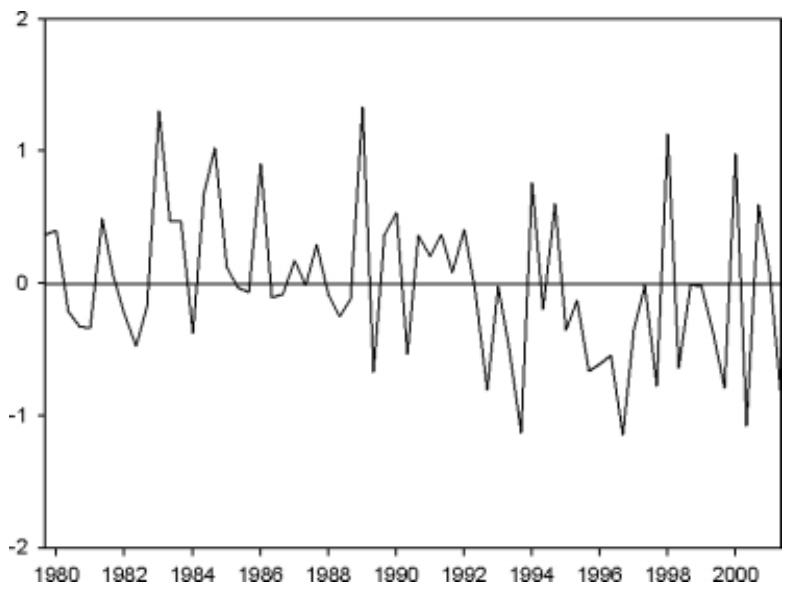

(c)

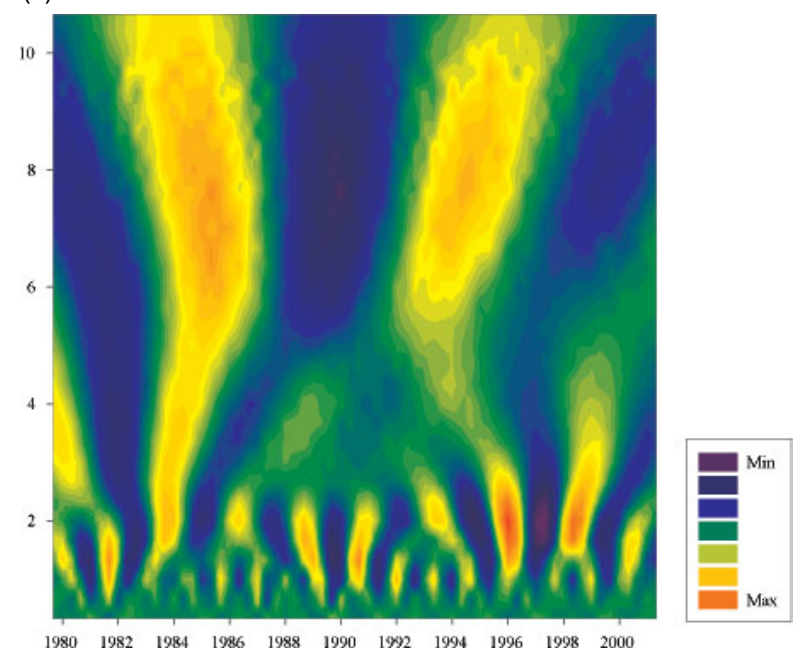

(b)

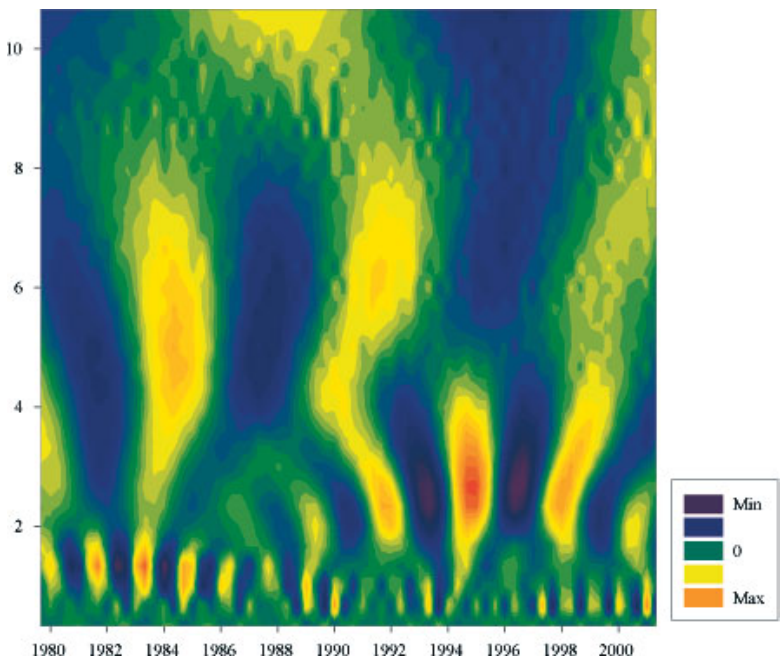

(d)

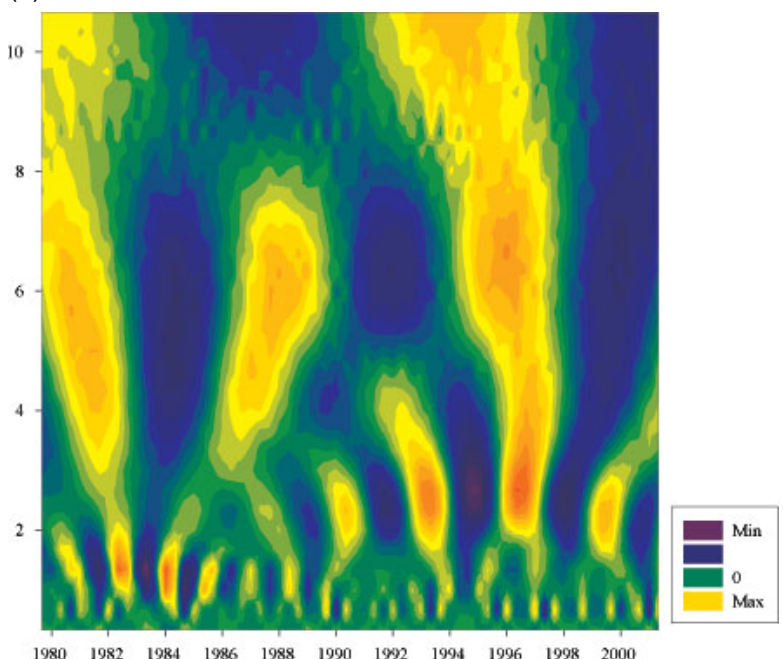

Figure 3. (a) Standardized wind time series spatially and temporally (March-May) averaged over Iberia. Units are in standard deviations in the $y$-axis and the $x$-axis corresponds to the time period. The wavelet power spectrum of the: (b) standardized wind time series displayed in (a); and (c) spring SCAN index and (d) wind expansion coefficient time series corresponding to Figure 2c (continuous line). The $y$-axis represents the variability scale (years), and the $x$-axis corresponds to the time period. This figure is available in colour online at wileyonlinelibrary.com/journal/joc

A correlation analysis between the spatial average of wind speed (Figure 3(a)) and the wind SVD1 time series [Figure 2(c), continuous line] gave an absolute value never below 0.8 as a result, indicating that the SVD1 seems to be strongly related to the long-term variability of mean wind in the area. Although neither significant periods are found after applying a spectral analysis to these time series nor significant trends are found after applying Mann-Kendall test (Goossens and Berger, 1986), the Morlet wavelet continuous analysis of all time series shows some remarkable characteristics [results only shown corresponding to time series of Figure 2(c), continuous line].

Figure 3(b) shows the wavelet power spectrum displayed as a function of period and time, corresponding to the wind time series spatially and temporally averaged over Iberia. The magnitude of wavelet coefficients gives a measure of the correlation between the signal and the wavelet basis. The power spectrum is mainly characterized by scales evolving between 3 and 8 years [see $y$-axis of Figure 3(b)], throughout the whole time period (1980-2001). Although power spectrum intensity is mainly concentrated in periods between 4 and 8 years, around 1984 arose some highly energetic amplitudes. Also a maximum nucleus between 1990 and 1992 it is noticeable, presenting a period with maximum amplitude at 6 years. The minima are located around 1993 and 1997 with scales evolving between 2 and 4 years, presenting minimum highly energetic oscillation. It is remarkable how pronounced peaks on these dates are also observed in the corresponding time series (Figure 3(a)). In fact, if Figure 3(a) and (b) are compared, it can be observed that the time location of wavelet maxima and minima match with above-normal and below-normal wind speed periods. Throughout the record, some episodes of quasibiennial oscillation (QBO) are found, lasting a short time. 
(a)
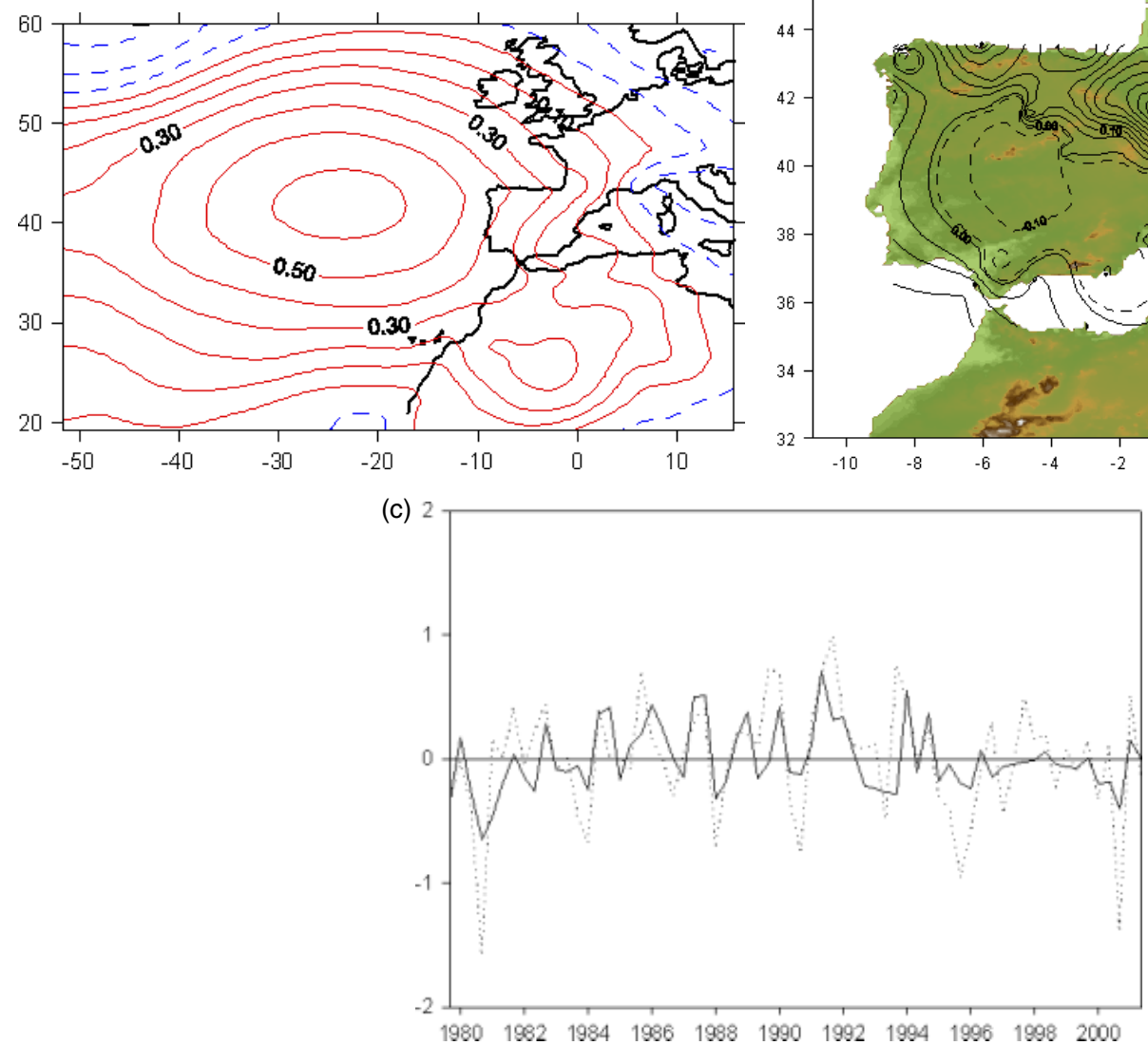

(b)

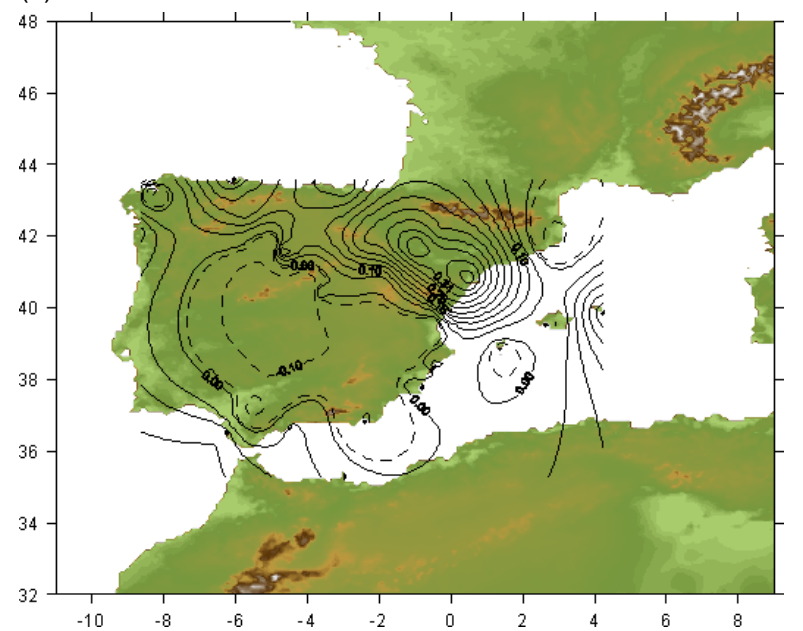

Figure 4. Same as Figure 2 except for the SVD2. This figure is available in colour online at wileyonlinelibrary.com/journal/joc

QBO signal predominates during the period 1990-2001, exhibiting high intensity around 1995. Additionally, periodograms of the time series were derived (not shown) to reveal that the maximum power of the spectra is concentrated in periods of less than 8 years, showing similarity with the wavelet results shown. If Figure 3(b) is compared with Figure 3(c), corresponding with the wavelet transform of the SCAN index, it can be noted similar evolution in their power spectrum nuclei. The power spectrum intensity (Figure 3(c)) is mainly concentrated in periods between 4 and 9 years, with highly energetic amplitude centred around 1984, being noticeable a maximum nucleus on 1994 with a period with maximum amplitude at 8 years. The power spectrum minima also present similarities with the corresponding minima of Figure 3(b). Like in this figure, throughout the record, some episodes of QBO are found, lasting a short time. QBO signal predominates during the period 1990-2001, exhibiting high intensity around 1996. Moreover, if Figure 3(b) and (c) is compared with Figure 3(d), inverse coherent zones in their wavelet power spectra can be observed. It is highlighted how the sequence of the maximum/minimum in the signal associated with Figure 3(b) is reversed to the corresponding signal in Figure 3(d) which corresponds with the wavelet spectrum of the wind expansion coefficient time series (Figure 2(c), continuous line). Such inverse information is also noted in the correlation between the two time series $(|r|>0.8)$ as it is abovementioned. The maxima/minima are found at the same scale and time values. They indicate that the wind expansion coefficient time series (Figure 2(c)) and the wind spatial average time series (Figure 3(a)) present analogous and inverse time-frequency evolution, and so the SVD1, related to the SCAN pattern, would explain the year-to-year fluctuations of the wind over the whole Iberia.

\subsection{Second mode of covariability}

The second SVD mode (SVD2) explains $14 \%$ of the SC between G1000 and wind fields (Table II). Figure 4(a) shows a strong nucleus of positive correlations located at Western Iberia which favour northwestern air masses advection over Iberia. Such northwestern advection is consistent with the corresponding wind heterogeneous pattern (Figure 4(b)) and presents an area of high positive correlations located over the northern of the study area with higher values over the Ebro Valley and negative ones in the central part of Iberia. This pattern reflects reinforcement of northwestern winds blowing 
down-valley Ebro, knowing this wind as Cierzo (Garcia, 1985). The wind SVD2 mode represents about 7\% of the total wind variance (Table III) and matches its corresponding homogeneous pattern (not shown) which accounts for $12 \%$ of the wind variability. On the other hand, the G1000 patterns described by the SVD2 mode explain $9 \%$ of variance, agreeing reasonably well with the corresponding homogeneous pattern which matches the well-known NAO teleconnection pattern (Barnston and Livezey, 1987), the main mode of low-frequency variability in the North Atlantic. In fact, the correlation between this heterogeneous pattern and the NAO configuration is 0.60 , indicating that the SVD2 relates the NAO teleconnection pattern to high positive wind correlations over the Northern Iberia.

Figure 4(c) displays the SVD2 time series. The correlation between the pairs of time series is 0.62 (Table II), bringing out a notable association between the G1000 and wind fields. Neither significant periods were found after applying a spectral analysis nor significant trends when applying the Mann-Kendall test to the time series. A continuous wavelet transform has been applied to both expansion coefficient time series of wind and the spring NAO index as it can be observed in Figure 5. The NAO power spectrum (Figure 5(a)) is mainly characterized by scales associated to low-frequency periods, showing power spectrum maxima mainly in periods between 5 and 9 years between 1990 and 1998. Figure 5(b) shows the wavelet power spectrum of the expansion coefficient time series of the wind field corresponding to the mode SVD2, depicting an opposite behaviour related to the high scales, i.e. to low frequency. It is noticeable how the lowfrequency signals associated with both time series are not in phase. In fact, while the NAO maximum highly energetic oscillations, associated with low-frequency periods, are distributed in the 1990 decade, the corresponding maxima of the wind SVD2 mode are located in

(a)

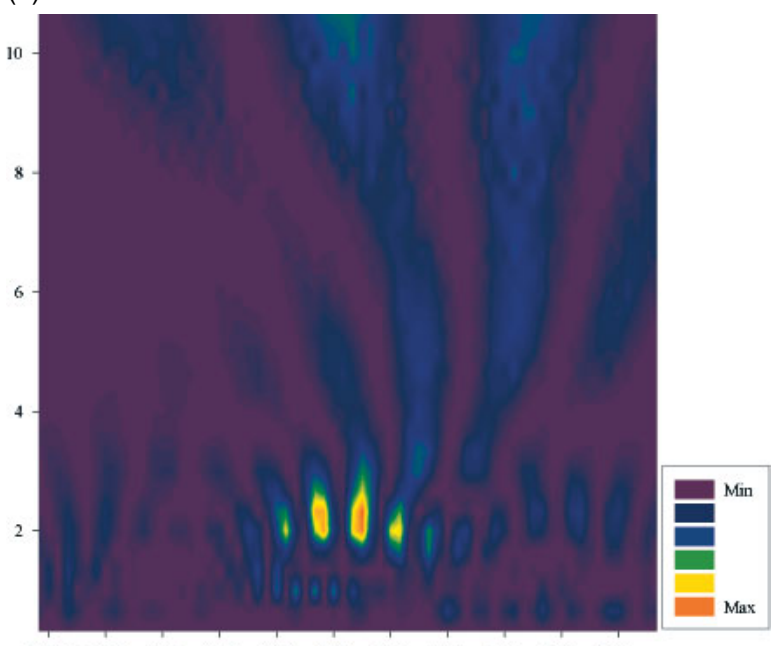

the first part of the record over the 1980 decade. Similar behaviour is also found when a discrete wavelet transform is applied to both NAO and expansion coefficient time series of wind (not shown), being both signals out of phase. On the other hand, episodes of high energetic oscillations are also found in high frequency. In the NAO case, there are zones of maximum intensity during the period 1988-1992, exhibiting the highest intensity around 1991. In the wind case (Figure 5(b)), the maximum areas are located over 1992-1995, with the highest intensity centred in 1993. Moreover, periodograms of the time series (not shown) are agree with the variability associated with low-frequency periods, showing significant variance between 6 and 10 years, and considerable variance associated with high frequency ( $<3$ years).

\subsection{Third mode of covariability}

The third SVD mode (SVD3) explains $8 \%$ of the SC between G1000 and wind fields. The G1000 pattern (Figure 6(a)) depicts two centres of correlations, one positive nucleus located southwesternward Iberia and another negative one over the Northern Atlantic Ocean. This configuration promotes warm advection over Iberia except for the most occidental area, favouring dissimilarity in the wind behaviour over Iberia as can be deduced from the corresponding heterogeneous wind pattern which depicts positive wind correlations in the western part of Iberia and negative ones over most of the Mediterranean Iberian coast (Figure 6(b)). This area is affected by warm advection and positive anomalies of geopotential, promoting negative anomalies of wind. The wind speed pattern described by the SVD3 mode accounts for about $4 \%$ of the total wind variance (Table III) and matches its homogeneous pattern (not shown) which accounts for 7\% of the wind variability. Although this third mode accounts lower SC between the surface atmospheric and regional fields than of the two first modes, it is worth to note that

(b)

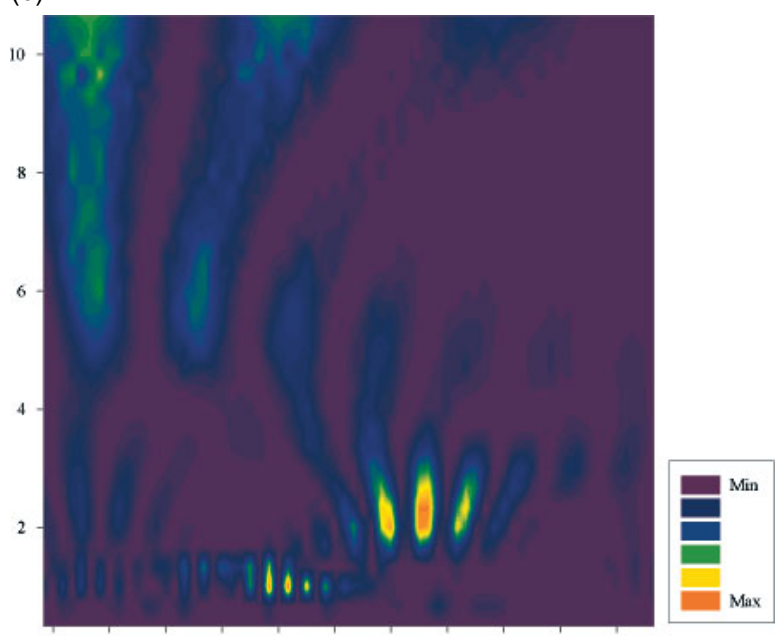

$\begin{array}{lllllllllll}1980 & 1982 & 1984 & 1986 & 1988 & 1990 & 1992 & 1994 & 1996 & 1998 & 2000\end{array}$

Figure 5. The wavelet power spectrum of the (a) spring NAO index and (b) wind expansion coefficient time series corresponding to Figure 4c (continuous line). The $y$-axis represents the variability scale (years) and the $x$-axis corresponds to the time period. This figure is available in colour online at wileyonlinelibrary.com/journal/joc 
(a)

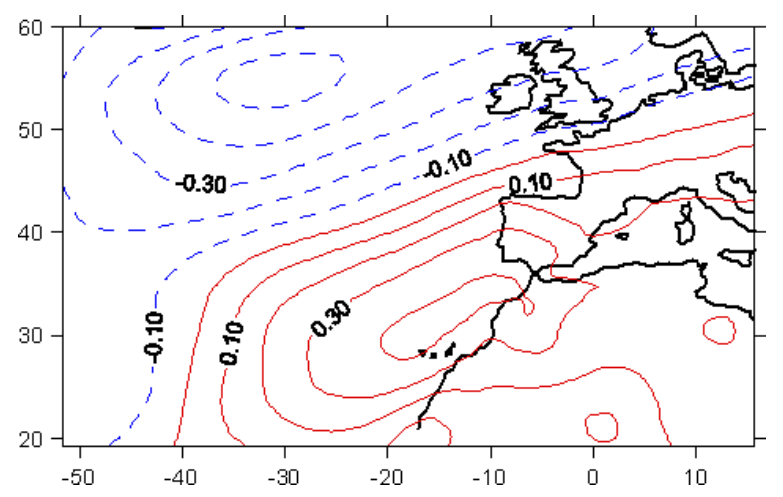

(b)

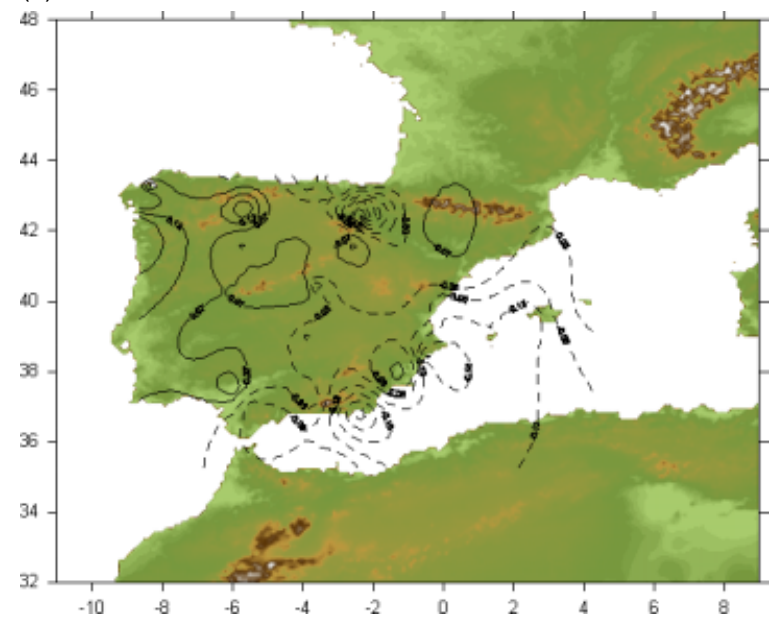

(c)

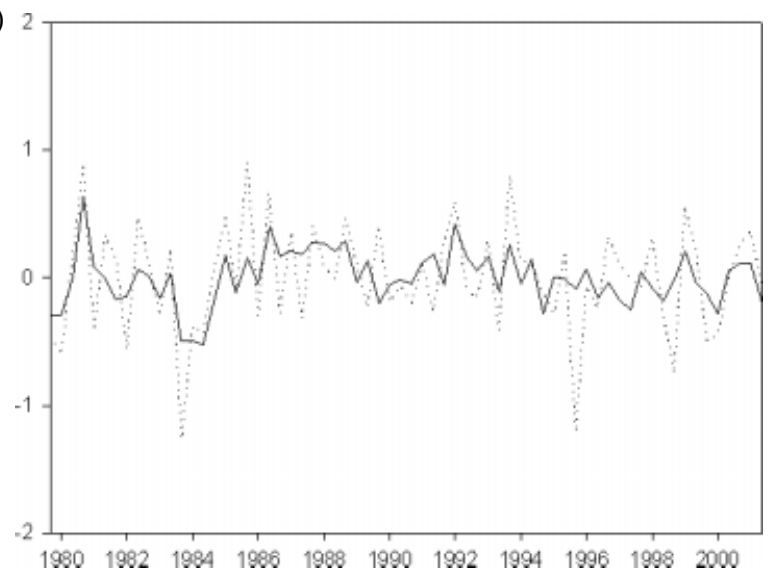

Figure 6. Same as Figure 2 except for the SVD3. This figure is available in colour online at wileyonlinelibrary.com/journal/joc

the associated G1000 pattern explains 7\% of variance and it matches to the well-known teleconnection pattern named East Atlantic (EA) pattern, similar to that shown in the study of Barnston and Livezey (1987). The EA pattern, the second main mode of low-frequency variability over the North Atlantic area, is prominent in all months. It is characterized in its positive phase by a north-south dipole of anomaly centres spanning from east to west of the North Atlantic area, shifting such centres southeastward to the approximate nodal lines of the NAO pattern. The southeastern nucleus gives information about the subtropical ridge and its important changes in intensity and location. The correlation value between the G1000 third expansion coefficient time series and the time series of the EA pattern is 0.51 , indicating that the SVD3 relates the wind in the Western and Mediterranean Iberian areas to the EA mode of variability.

The SVD3 time series (Figure 6(c)) show similar time evolution with quite high correlation values $(r=0.62)$ between the pairs of time series (Table II), suggesting a high degree of coupling between the large-scale variable and the regional wind. The power wavelet spectrum of the EA index (Figure 7(a)) presents significant signal in scales between 2 and 5 years throughout the time record, showing power spectrum maximum mainly concentrated in periods of 3 years with remarkable maxima between
1990 and 1996. For more high-frequency periods (below 2 years), there is a sequence of maximum zones from 1990 to 2000 , with the highest intensity located around 1999. On the other hand, the wavelet spectrum of the expansion coefficient time series of the wind field corresponding to the mode SVD3 (Figure 7(b)) displays maximum highly energetic oscillations distributed in the 1980 decade. The EA and the wind SVD3 spectra show some common signals in scales distributed between 3 and 6 years. The wind SVD3 spectrum shows maximum highly energetic oscillations at 5 years in the 1980 decade while the EA spectrum shows little variance in such period. Throughout the record, short time episodes of QBO are again observed in Figure 7(b), predominating from 1980 to 1984 and exhibiting high intensity around 1982. Periodograms of time series were also derived (not shown), revealing similarity with the wavelet results shown.

In order to give a statistical significance of the SVD results and to indicate the genuine and not artificial result of a statistical methodology, it is necessary to analyse the statistical robustness of the mode. To do this, a procedure based on a Monte Carlo approach is applied. As it is abovementioned in the previous section, it will be used the SC instead of the SCF or the correlation coefficient, $r$. While the SCF and $r$ are indirect measures 
(a)

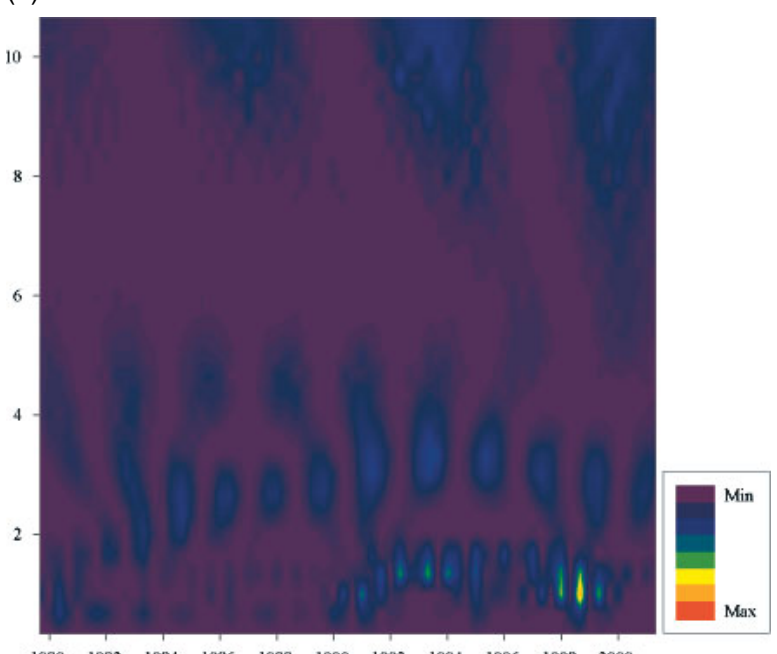

(b)

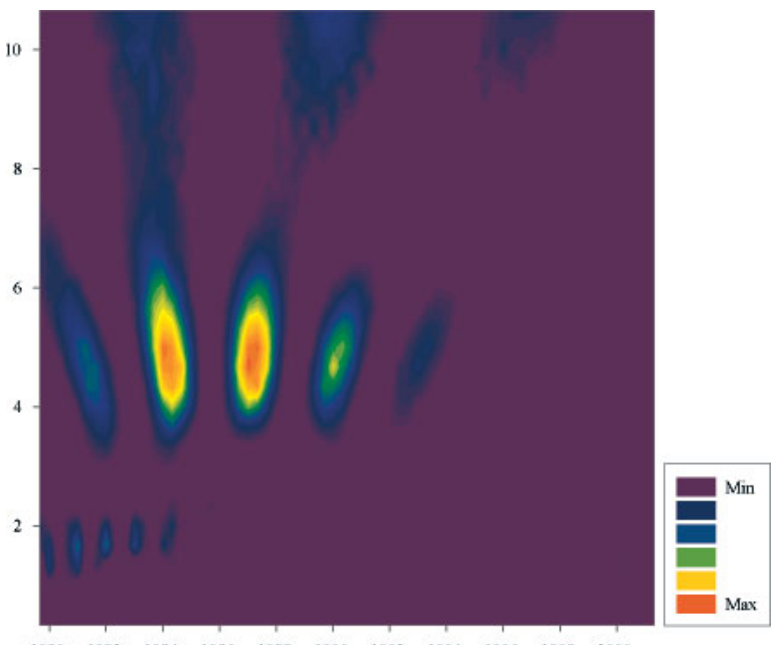

Figure 7. The wavelet power spectrum of the (a) spring EA index and (b) wind expansion coefficient time series corresponding to Figure 6(c) (continuous line). The $y$-axis represents the variability scale (years) and the $x$-axis corresponds to the time period. This figure is available in colour online at wileyonlinelibrary.com/journal/joc

of the relationship between the SVDA modes, the SC is a direct measure of the relationship between the surface and wind fields and between the coupled SVD patterns. Following the procedure, 100 scrambled datasets are built by only scrambling each synoptic G1000 pattern of 22 years, destroying its chronology relative to the wind field. Then, an SVD is performed over each scrambled dataset and the wind speed field, doing consequently 100 SVDs, comparing the 100 SVDs results with those obtained from the original unscrambled data. The SC from the observed G1000 field and the wind dataset is considered statistically significant at the $95 \%$ level if it is not exceed more than five times by the corresponding ones from the 100 scrambled datasets. Here, the results of the 100 scrambled SVDs and the corresponding results from the original SVDs based on the observed data have shown that the total SC of the original datasets exceeds the $95 \%$ significance level for the synoptic field (Figure 8), thereby suggesting that the detected relationship between wind speed in the Iberian Peninsula and surface circulation is highly significant. Moreover, only the SC values corresponding to the three first coupled modes of G1000/wind are found to be significant at the $95 \%$ level as it can be noted in Figure 8 in which the original SC values, joined by continuous line, are higher than the SC values of scrambled data. Although the second and third SVD modes account for low SCF (but significant $r$ ) when they are compared with the first leading mode, their obtained SCs show significant higher values than the associated scrambled $\mathrm{SC}$, indicating meaningfulness of their SCF and $r$. These results imply that the Iberian wind field response to dynamical atmospheric processes, involved in G1000, is effective. Thus, the coupling obtained from the SVD patterns between the Iberian wind field and large-scale surface atmospheric circulation is genuine and not an artificial result of a statistical methodology.

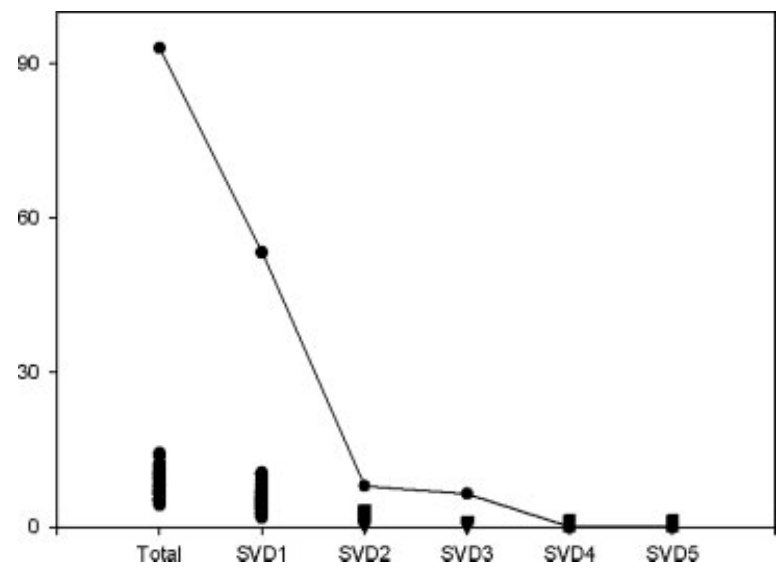

Figure 8. SC values corresponding to the total contribution of the first five SVD modes of the original datasets (joined by continuous line) as well as the contribution of each independent mode of the 100 randomly SVDs (dotted). The $y$-axis represents SC $\left(\times 10^{-2}\right)$ values.

\section{Results from Composite Maps. Relationship between Wind and Large-Scale Atmospheric Circulation}

To examine the relationship between observational patterns and the coupled obtained SVD modes, positive (negative) composites of the distribution of G1000 and wind anomalies are constructed from the 5\% highest (lowest) expansion coefficients to give an 'average' pattern associated with extreme conditions.

Figure 9 shows the SVD1 composite maps. The positive composite maps for the first mode (Figure 9(a) and (b)) show in the G1000 pattern a blocking pattern configuration with a nucleus of positive anomaly centred over Western Europe (Bluestein, 1993). This pattern supports eastern advection of air mass over the Iberian Peninsula. The anomaly wind field (Figure 9(b)) presents negative wind anomalies in the whole area except for the Southern Iberia area in which it can be noted differences because 
(a)

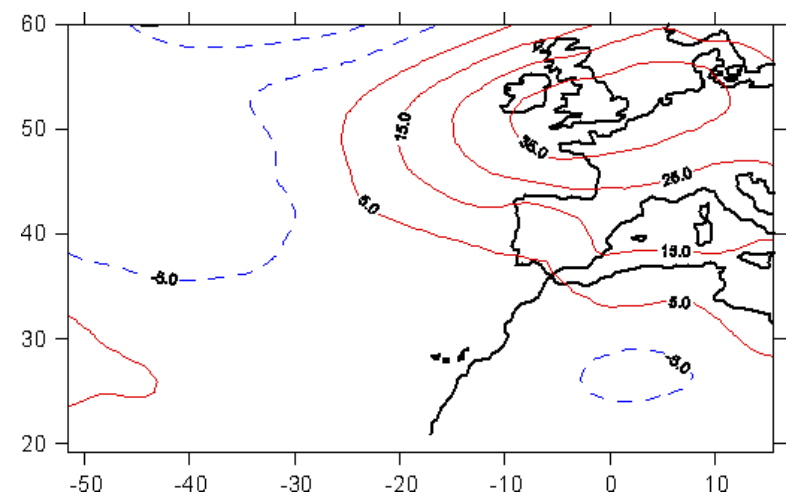

(c)

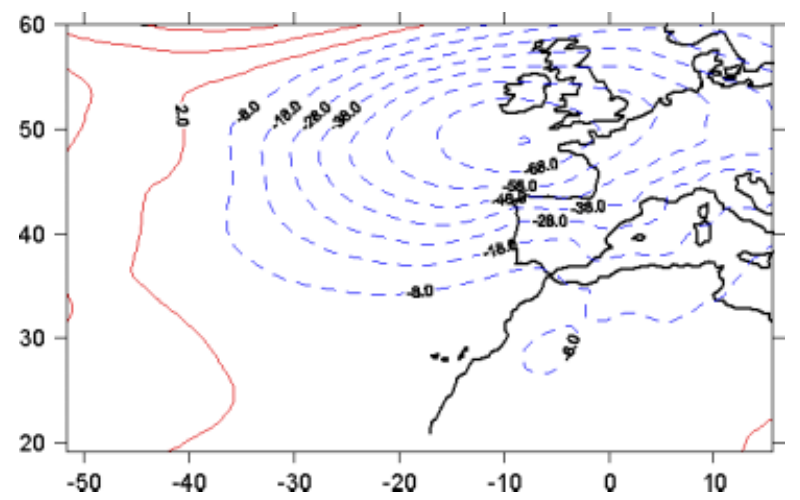

(b)

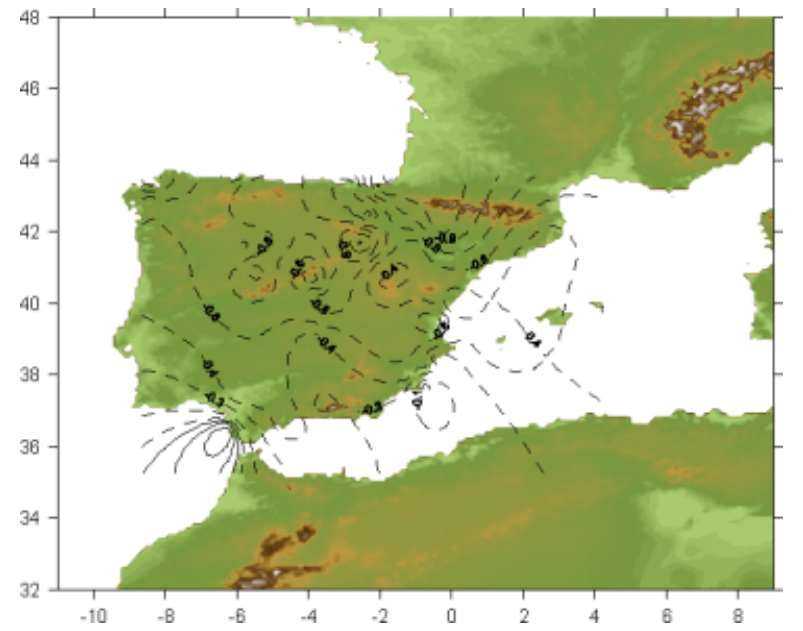

(d)

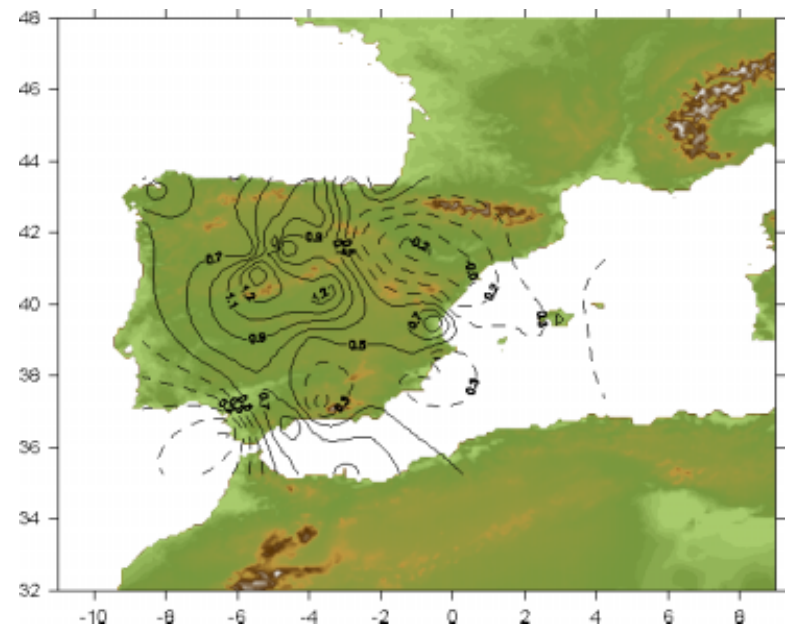

Figure 9. Composite anomaly maps of the first mode: (a) G1000 (gpm) and (b) wind ( $\mathrm{m} \mathrm{s}^{-1}$ ) corresponding to the positive composite. (c) G1000 $(\mathrm{gpm})$ and $(\mathrm{d})$ wind $\left(\mathrm{m} \mathrm{s}^{-1}\right)$ corresponding to the negative composite. This figure is available in colour online at wileyonlinelibrary.com/journal/joc

of the Gibraltar Strait effect. Alternatively, negative composites are shown in Figure 9(c) and (d). The G1000 pattern shows a strong nucleus of negative anomalies located eastern Atlantic Ocean, promoting negative anomalies, i.e. below-normal wind values over the Ebro Valley and Gibraltar area and positive ones in the Iberian core. The large-scale configuration favours the presence of Cierzo, western moist winds blowing down-valley Ebro as it can be observed in Figure 9(d).

For the SVD2 composite maps (Figure 10), it is remarkable how the coupled SVD mode configurations (Figure 4) are reproducible in the corresponding composite maps. Thus, Figure 10(a) shows a strong centre of positive anomalies in the G1000 pattern located over the Atlantic Ocean, favouring northern wind over Iberia as it can be noted in the corresponding composite map (Figure 10(b)). Figure 10(c) and (d) corresponds to the composite data for the G1000 and wind anomalies obtained from the negative phase of the second mode. In Figure 10(c), a strong nucleus of negative G1000 anomalies are situated over the Atlantic area, promoting southwestern wind over Iberia. In Figure 10(d), positive wind anomalies are located in the inner of Iberia changing the anomaly signs at northern and southern area of the Iberian Peninsula. Observational wind data corresponding to these composite patterns have shown values of around 7 and $5 \mathrm{~m} \mathrm{~s}^{-1}$ over the northern area of study. Such data are higher than the median and the average of the observational wind data, indicating that the high wind speed episodes in the Iberian Peninsula are related to the large-scale obtained configurations.

For the third SVD mode, the composite maps are displayed in Figure 11. The positive composite G1000 map (Figure 11(a)) shows similar configuration at that one obtained for the SVD3 mode, exhibiting a north-south dipole of negative-positive anomalies. Its corresponding wind composite (Figure 11(b)) is characterized by moderately anomaly values of wind over Iberia with north-south differences in the wind field behaviour. Alternatively, Figure 11(c) shows same distribution of G1000 isolines with reverse sign, showing several cores of moderate wind values in the northern Iberia (Figure 11(d)). In fact, observational wind data corresponding to these composite patterns have shown 
(a)

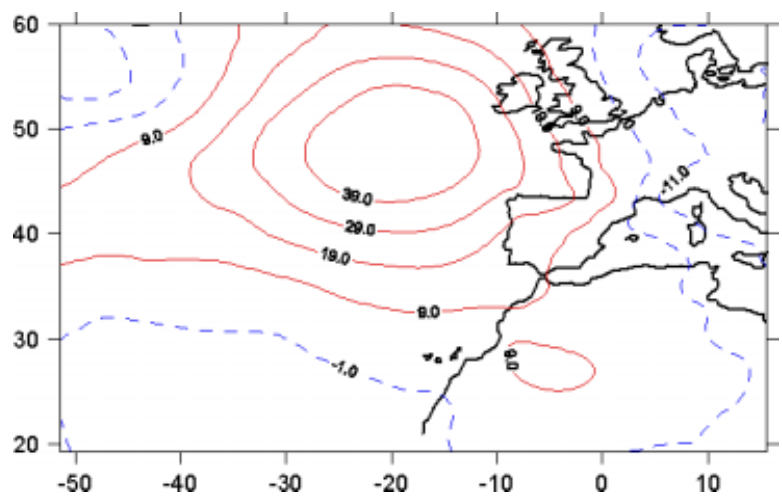

(c)

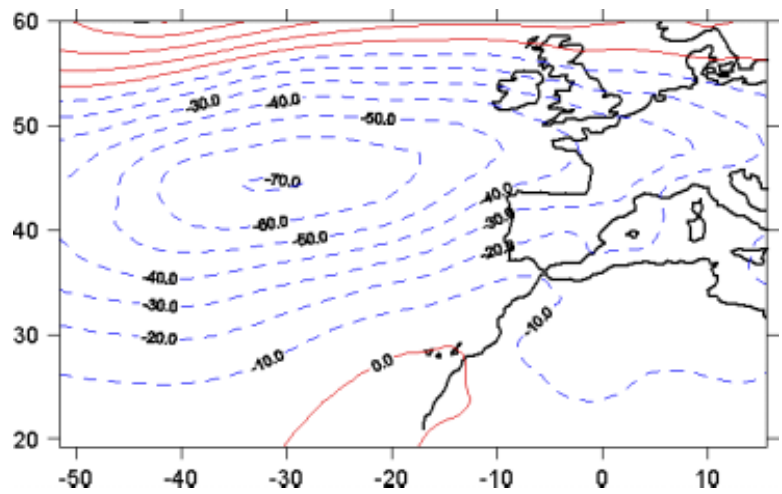

(b)

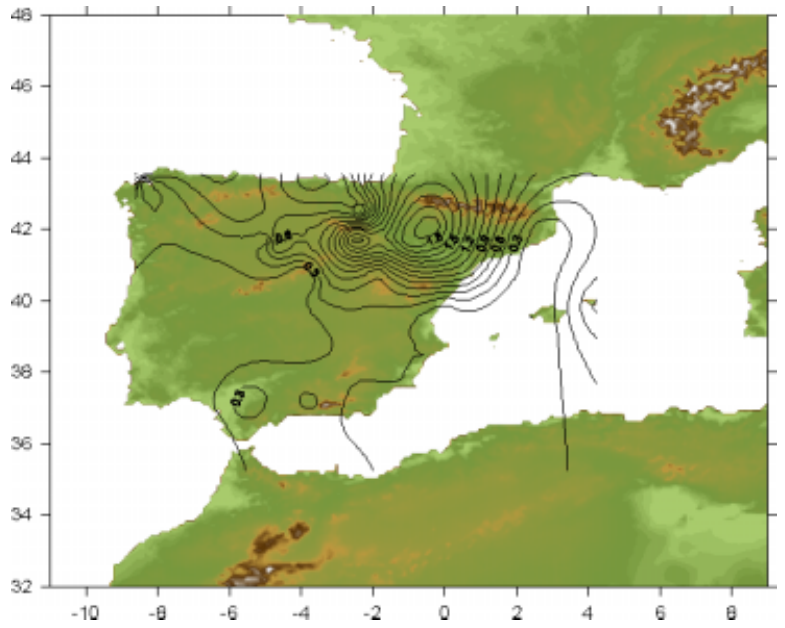

(d)

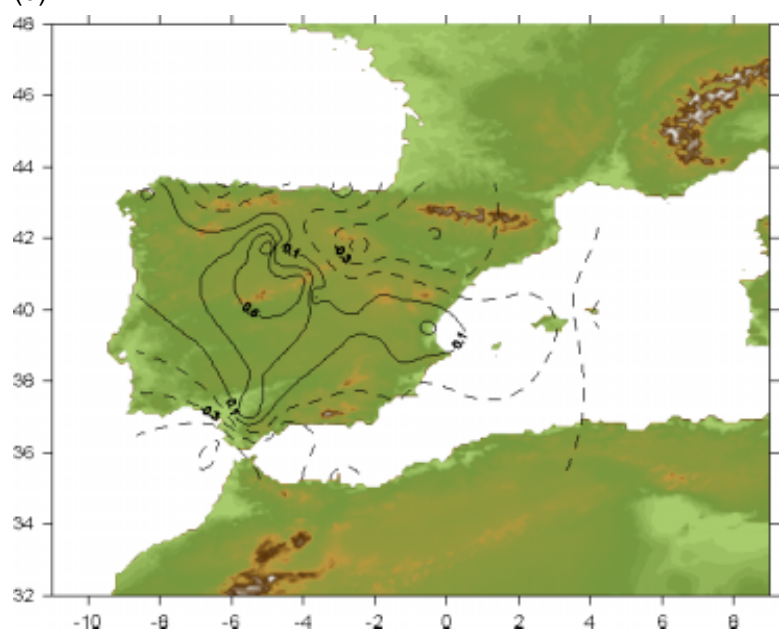

Figure 10. Same as Figure 9 except for the second mode. This figure is available in colour online at wileyonlinelibrary.com/journal/joc

values between 2 and $5 \mathrm{~m} \mathrm{~s}^{-1}$ over the area of study which are lower than the median and the average of the observational wind data.

\section{Summary and Discussion}

The relationship between spring wind over the Iberian Peninsula and Balearics and surface atmospheric circulation has been examined by means of the SVD analysis. In order to characterize the atmospheric circulation, monthly mean geopotential heights of 22 springs from 1980 to 2001 have been used. For the same period, monthly mean wind speed time series of 48 sites covering mainly Iberia and the Balearic Islands have been considered. Three modes have been obtained and described in the context of known tropospheric teleconnection patterns. They explain over $93 \%$ of the total covariability between the atmospheric variables and the Iberian wind field and almost $35 \%$ of the wind variability itself. The results of this study imply that the atmospheric conditions in the North Atlantic and the wind speed over Iberia display three different modes of interaction.
The first SVD mode indicates that below-normal wind values are determined by the presence of a longlived blocking pattern characterized by strong nucleus of correlations centred eastern ward British Isles. The synoptic pattern obtained from the first SVD mode matched the negative phase of the SCAN teleconnection pattern with an absolute correlation value of 0.6 between the synoptic first expansion coefficient time series and the time series of the SCAN pattern. Thus, the SVD1 mode captures the Iberian wind variability linked to SCAN variability. The second SVD mode establishes a clear relationship between the heterogeneous G1000 and the NAO patterns, with a correlation value of 0.60 , resembling a configuration with a positive node of high correlation values spanning central latitudes of the North Atlantic Ocean. This large-scale atmospheric distribution promotes advection of NW air over the Iberian area, favouring the presence of Cierzo because of the channelling effect of the wind blowing down-valley Ebro. Thus, the heterogeneous wind pattern displays an area of high positive correlations located over the northern of the study area with higher values over the Ebro Valley and negative ones in the central part 
(a)

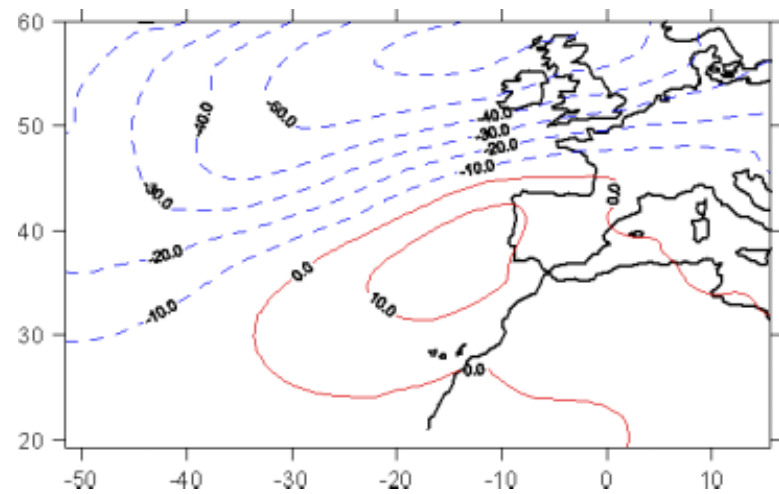

(c)

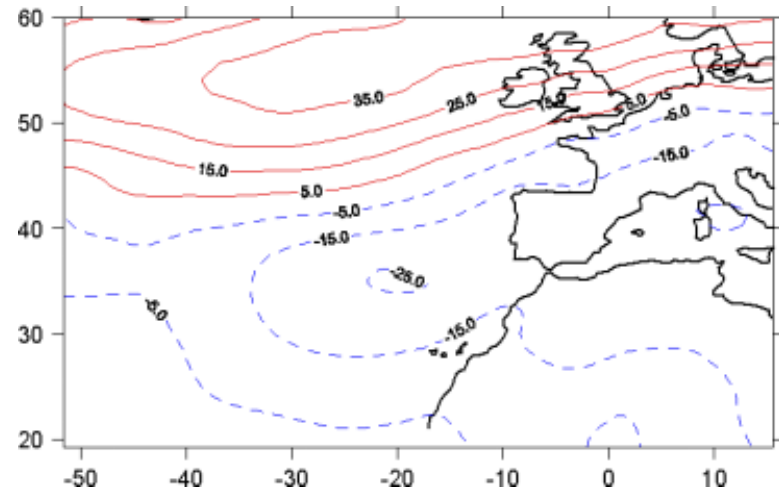

(b)

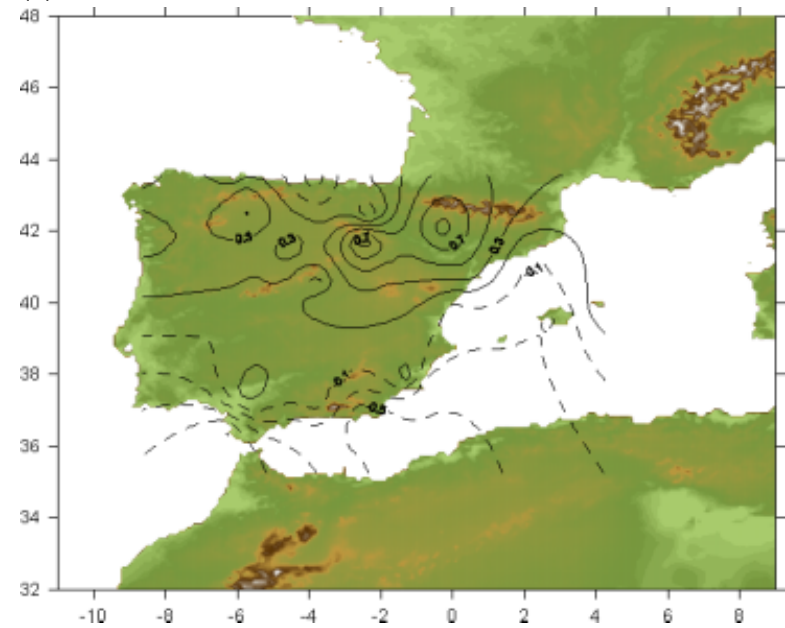

(d)

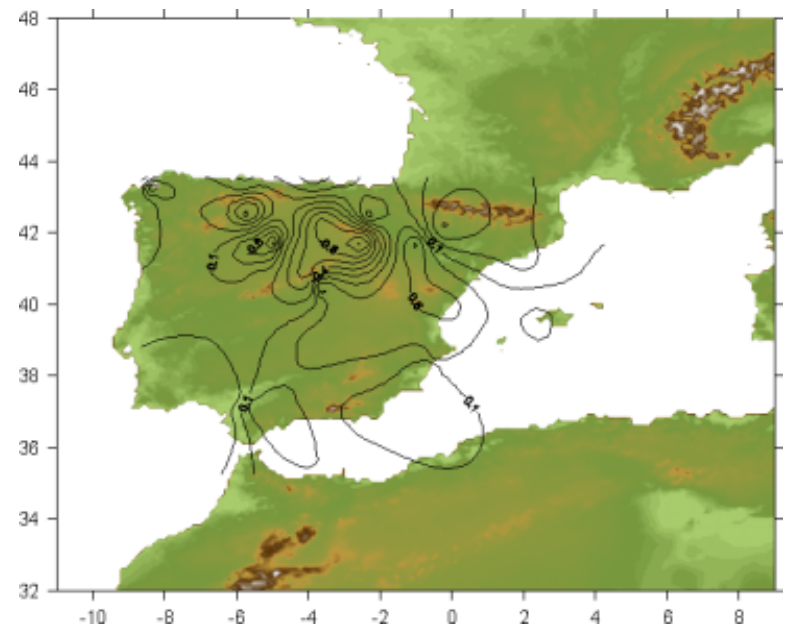

Figure 11. Same as Figure 9 except for the third mode. This figure is available in colour online at wileyonlinelibrary.com/journal/joc

of Iberia. These results indicate that this SVD2 mode would explain the response of the study area to the NAO pattern, i.e. an intensification (weakening) of the spring NAO index is linked with positive (negative) wind correlations over the northern (southern) area of study. The third SVD mode depicts in its G1000 pattern two centres of correlations, one positive nucleus located southwesternward Iberia and another negative nucleus spanning high latitudes of the North Atlantic Ocean. Thus, SW warm air masses are advected over Iberia, favouring contrasted wind behaviour in the Peninsula with positive wind correlations in the western part of Iberia and negative values over most of the Mediterranean Iberian coast. In spite of the lower SC between the large-scale and regional fields, the heterogeneous G1000 pattern matches to the EA pattern with a correlation value of 0.51 between the G1000 third expansion coefficient time series and the time series of the EA pattern. This situation would indicate that the third SVD mode relates the wind in the Western and Mediterranean Iberian areas to the EA mode of variability. Additionally, a Monte Carlo test was performed to assess the statistical robustness of the statistically obtained SVD results. The test has determined the statistical significance of the three leading SVD modes and has indirectly estimated the relative importance of the synoptic atmospheric circulation over the Iberian wind field.

Additional information related to the temporal evolution of the obtained SVD modes can be extracted from the analysis of the expansion coefficient time series. A wavelet analysis has been performed over the expansion coefficient time series of the three obtained modes. The SVD1 mode could be responsible for the year-toyear wind fluctuations on the study area. For the wind speed time series spatially and temporally averaged over Iberia and the wind expansion coefficient time series of mode 1, wavelet transforms have been applied, highlight the inverse sequence of the maximum/minimum in both signals at the same scale and time values. This reverse information was also noted in the absolute correlation value of 0.8 obtained between the two time series. Therefore, it can be seen that the wind expansion coefficient time series of this SVD1 and the wind speed spatial average time series present analogous and inverse timefrequency evolution and thus, the SVD1 would explain the year-to-year fluctuations of the wind of the whole 
Iberia. For the second SVD mode, the wavelet transforms, applied to both wind expansion coefficient time series and the spring NAO index, show a reverse behaviour related to high scales, being out of phase the low-frequency signals associated to both time series. The NAO maximum highly energetic oscillations are distributed in the 1990 decade while the corresponding maximum of the wind SVD mode can be observed in the 1980 decade. Concerning the lower scales, episodes of high energetic oscillations predominate from 1987 till the end of the record in the NAO case and during the period 1990-1996 for the wind, exhibiting high intensity around 1993.

Hurrell and van Loon (1997) analysed the influence of oscillating values of the winter NAO index in the North Hemisphere with particular attention in precipitation and temperature over the Atlantic area. Time series of the winter NAO index (1864-1995) and the corresponding power spectrum were analysed, revealing decadal changes in the NAO index with significant variance at biennial periods in the first part of the record, whereas the 6-10 variance was enhanced over the latter half of the 20th century (Hurrell and van Loon, 1997). Although the NAO is most pronounced during winter, this paper has revealed a strong seasonal relationship between this teleconnection index and the Iberian wind during the springtime. Like in the spectrum winter results of Hurrell and van Loon (1997), the variability associated with low frequency, shown in the wavelet of the NAO-second SVD wind mode, revealed reverse behaviour related to high time scales in this paper. Thus, while the variability associated with low-frequency period was highlighted in the NAO index in the 1990 decade, here the remarkable variability of the wind SVD mode wavelet spectrum appeared in the 1980 decade. Positive values of the NAO index are indicative of stronger than average westerlies over the middle latitude areas which are associated with anomalies of low pressures over the Icelandic and strong anomalies of high pressures over the subtropical Atlantic. This can be noticed on the reverse behaviour of the Iberian wind field at low frequency. Alterations in the North Atlantic mean circulation patterns go with marked shifts in the storm tracks and their related large-scale eddy activity (Hurrell, 1995; Rogers and Mosley-Thompson, 1995). If the anticyclonic (cyclonic) behaviour over Iberia is long time reinforced, the wind field will present periods of calm (windy) over most of the Iberian Peninsula.

Finally, for the third SVD mode, the EA power wavelet spectrum presents throughout the time record significant signal in scales between 2 and 5 years with maximum mainly concentrated in periods of 3 years with remarkable intensity between 1990 and 1996. The corresponding wavelet spectrum of the SVD wind presents maximum highly energetic oscillations in the 1980 decade in periods of 5 years. Both wavelet spectra have shown some common signal in scales distributed between 3 and 6 years with different amplitudes between them. Short QBO episodes are observed with a predominance between 1980 and 1984 and high intensity around 1982.
The analyses have revealed the strong influence of the pressure centres over the Atlantic Ocean in the Iberian wind field, identifying different atmospheric circulation patterns that govern the wind variability at the Iberian Peninsula during the spring season. Thus, the coupling between the first SVD mode and the SCAN pattern dominates the covariability between the two fields. The second SVD mode accounted for smaller covariability, but it indicated how the regional wind speed responds to the NAO pattern, and, finally, even though the third SVD mode accounts for the smallest but significant covariability, it indicated the coupling between such G1000/wind patterns and the EA pattern. The SVD analysis has shown that the atmospheric dynamics in the North Atlantic is responsible for more than $30 \%$ of the wind variance in the Iberian Peninsula. The variation of intensity and/or position of pressure centres, within a climate change scenario, could possibly change the relative frequency of the large-scale atmospheric patterns or form new ones, changing the present wind regime.

\section{Acknowledgements}

This work has been partially supported by the research projects CGL2007-61328/CLI and UE SafeWind Grant Agreement No. 213740. Two anonymous reviewers provided helpful comments and suggestions. The authors wish to thank the following institutions which provided us with data: ERA40 from the European Center for Weather Medium Forecast (ECWMF), the Iberian Wind Dataset from the Spanish Meteorological Service (AEMET: Agencia Estatal de Meteorología, Spain) and the teleconnection indices by the U.S. Climate Prediction Center from the web site http://www.cpc.noaa.gov/data/ teledoc/telecontents.shtml.

\section{References}

Barbosa SM, Silva ME, Fernandes MJ. 2009. Multi-scale variability patterns in NCEP/NCAR reanálisis sea-level pressure. Theoretical Applied Meteorology 96: 319-326, DOI: 10.1007/s00704-008-00424.

Barnston AG, Livezey RE. 1987. Classification, seasonality and persistence of low-frequency atmospheric circulation patterns. Montlhy Weather Review 115: 1083-1126.

Bluestein HB. 1993. Synoptic dynamic meteorology in midlatitudes. Observations and Theory of Weather Systems, vol. II. Oxford University Press: New York; 594.

Bretherton CS, Smith C, Wallace JM. 1992. An intercomparison of methods for finding coupled patterns in climate data. Journal of Climate 5: 541-560.

Corte-Real J, Zhang X, Wang X. 1995. Large-scale circulation regimes and surface climatic anomalies over the Mediterranean. International Journal of Climatology 15: 1135-1150.

Davis R. 1976. Predictability of sea surface temperature and sea level pressure anomalies over the Northern Hemisphere. Journal of Physical Oceanography 6: 249-266.

Deser C, Blackmon ML. 1993. Surface climate variations over the North Atlantic ocean during winter: 1900-1989. Journal of Climate 6: $1743-1753$.

Esteban-Parra MJ, Rodrigo FS, Castro-Diez Y. 1998. Spatial and temporal patterns of precipitation in Spain for the period 1880-1992. International Journal of Climatology 18: 1557-1574.

Font I. 2000. Climatología de España y Portugal, 2nd edn. Ediciones Universidad de Salamanca: Spain; 422. 
Gamage N, Blumen W. 1993. Comparative analysis of low-level cold fronts: Wavelets, Fourier, and empirical orthogonal function decomposition. Monthly Weather Review 121: 2867-2878.

Garcia L. 1985. La predicción del tiempo en el Valle del Ebro. Technical Report Series A, No 38, INM, Madrid.

Gao W, Li BL. 1993. Wavelet analysis of coherent structures at the atmosphere-forest interface. Journal of Applied Meteorology 32 $1717-1725$.

Gibson JK, Kallberg P, Uppala S, Hernandez A, Ñomura A, Serrano E. 1997. ERA description. Technical Report Re-analysis Project Report Series 1, ECMWF, Reading, UK.

Glowienka-Hence R. 1990. The North Atlantic Oscillation in the Atlantic-European SLP. Tellus 42: 497-507.

Goossens C, Berger A. 1986. Annual and seasonal climatic variations over the Norther Hemisphere and Europe during the last century. Annales Geophysicae 4: 385-400.

Grossman A, Morlet J. 1984. Decomposition of Hardy functions into square integrable wavelets of constant shape. SIAM Journal of Mathematical Analysis 15: 732-736.

Heyen H, Zorita E, von Storch H. 1996. Statistical downscaling of monthly mean North Atlantic air-pressure to sea level anomalies in the Baltic Sea. Tellus 48A: 312-323.

Holton JR. 1992. An Introduction to Dynamic Meteorology. 3rd edn, International Geophysics Series 48. Adademic Press: New York; 511.

$\mathrm{Hu}$ Q. 1997. On the uniqueness of the singular value decomposition in meteorological applications. Journal of Climate 10: 1762-1766.

Hurrell JW. 1995. Transient eddy forcing of the rotational flow during northern winter. Journal of the Atmospheric Sciences 52: 2286-2301.

Hurrell JW, van Loon H. 1997. Decadal variations in climate associated with the north Atlantic Oscillation. Climate Change 36: 301-326.

Kaiser G. 1995. A Friendly Guide to Wavelets. Birkhauser: Boston; 300.

Lorenz E. 1956. Empirical orthogonal functions and statistical weather prediction. Scientific Report No. 1, Statistical forecasting Project. Department of Meteorology, MIT: Cambridge, Mass; 49.

Luna MY, Martín ML, Valero F, González-Rouco F. 2001. Wintertime Iberian Peninsula precipitation variability and its relation to North Atlantic Atmospheric circulation. In: Detecting and Modelling Regional Climate Change and Associated Impacts, Brunet $\mathrm{M}$, López D (eds). Springer-Verlag: Berlin; 369-376.

Maheras P, Flocas HA, Patrikas I, Anagnostopoulou C. 2001. A 40 year objective climatology of surface cyclones in the Mediterranean region: spatial and temporal distribution. International Journal of Climatology 21: 109-130.

Mallat S. 1998. A Wavelet Tour of Signal Processing. Academic Press: New York; 637.

Martin ML, Luna MY, Morata A, Valero F. 2004. North Atlantic teleconnection patterns of low-frequency variability and their links with springtime precipitation in the western Mediterranean. International Journal of Climatology. 24: 213-230, DOI: 10.1002/joc.993.

Morata A, Martín ML, Luna MY, Valero F. 2006. Self-similarity patterns of precipitation in the Iberian Peninsula. Theoretical and Applied Climatology 85: 41-59, DOI: 10.1007/s00704-005-0175-7.
Morata A, Martín ML, Sotillo M, Valero F, Luna MY. 2008. Iberian autumn precipitation characterization through observed, simulated and reanalysed data. Advances in Geosciences. 16: 49-54, http://www.adv-geosci.net/16/49/2008/.

Morlet GA, Fourgeau I, Giard D. 1982. Wave propagation and sampling theory. Geophysics 47: 203-236.

Palutikof JP, Kelly PM, Davies TD, Halliday JA. 1987. Impacts of spatial and temporal windspeed variability on wind energy output. Journal of Applied Meteorology 26: 1124-1133.

Rodriguez-Puebla C, Encinas AH, Nieto S, Garmendia J. 1998. Spatial and temporal patterns of annual precipitation variability over the Iberian Peninsula. International Journal of Climatology 18: 299-316.

Rogers JC. 1990. Patterns of low-frequency monthly sea level pressure variability (1899-1986) and associated wave cyclone frequencies. Journal of Climate 3: 1364-1379.

Rogers JC, Mosley-Thompson E. 1995. Atlantic Artic cyclones and the mild Siberian winters of the 1980s. Geophysical Research Letters 22: 799-802.

Simmons AJ, Gibson JK. 2000. The ERA-40 Project Plan. ERA-40 Project Report Series No. 1. ECMWF, Reading, UK.

Sotillo MG, Martín ML, Valero F, Luna MY. 2006. Validation of an homogeneous 41-year (1961-2001) winter precipitation hindcasted dataset over the Iberian Peninsula: assessment of the regional improvement of global reanalysis. Climate Dynamics 27: 627-645, DOI: $10.1997 / \mathrm{s} 00382-006-0155-3$.

von Storch H, Zwiers FW. 1999. Statistical Analysis in Climate Research. Cambridge University Press: UK.

von Storch H, Navarra A. 1995. Analysis of Climate Variability. Applications of Statistical Techniques. Springer-Verlag: Berlin; 334.

Thuillier RH. 1987. Real-time of local wind patterns for application to nuclear-emergency response. Bulletin of the American Meteorological Society 68: 1111-1115.

Valero F, Luna MY, Martín ML, Morata A, González-Rouco F. 2004. Coupled modes of large-scale climatic variables and regional precipitation in the Western Mediterranean in autumn. Climate Dynamics 22: 307-323, DOI 10.1007/s00382-003-0382-9.

Valero F, Martín ML, Sotillo MG, Morata A, Luna MY. 2009. Characterization of the autumn Iberian precipitation from longterm data sets: comparison between observed and hindcasted data. International Journal of Climatology 29: 527-541, DOI: 10.1002/joc.1526, DOI: 10.1002/joc. 1726.

Wallace JM, Smith C, Bretherton CS. 1992. Singular value decomposition of wintertime sea surface temperature and 500-mb height anomalies. Journal of Climate 5: 561-576.

Weng H, Lau KM. 1994. Wavelets, period doubling and timefrequency localization with application to organization of convection over the tropical western Pacific. Journal of Atmospheric Sciences 51: $2523-2541$

Zuranski JA, Jaspinka B. 1996. Directional analysis of extreme wind speeds in Poland. Journal of Wind Engineering and Industrial Aerodynamics 65: 13-20. 